\title{
Neurocircuitry of Mood Disorders
}

\author{
Joseph L Price ${ }^{\star, 1}$ and Wayne C Drevets ${ }^{2}$ \\ ${ }^{1}$ Department of Anatomy and Neurobiology, Washington University School of Medicine, St Louis, MO, USA; \\ ${ }^{2}$ Section on Neuroimaging in Mood and Anxiety Disorders, National Institute of Mental Health National Institutes of Health, \\ Bethesda, MD, USA
}

\begin{abstract}
This review begins with a brief historical overview of attempts in the first half of the 20th century to discern brain systems that underlie emotion and emotional behavior. These early studies identified the amygdala, hippocampus, and other parts of what was termed the 'limbic' system as central parts of the emotional brain. Detailed connectional data on this system began to be obtained in the 1970s and 1980s, as more effective neuroanatomical techniques based on axonal transport became available. In the last 15 years these methods have been applied extensively to the limbic system and prefrontal cortex of monkeys, and much more specific circuits have been defined. In particular, a system has been described that links the medial prefrontal cortex and a few related cortical areas to the amygdala, the ventral striatum and pallidum, the medial thalamus, the hypothalamus, and the periaqueductal gray and other parts of the brainstem. A large body of human data from functional and structural imaging, as well as analysis of lesions and histological material indicates that this system is centrally involved in mood disorders.
\end{abstract}

Neuropsychopharmacology Reviews (2010) 35, 192-216; doi: 10.1 038/npp.2009. 104; published online 19 August 2009

Keywords: limbic system; amygdala; medial prefrontal cortex; major depressive disorder; neuroimaging; bipolar disorder

\section{OVERVIEW OF CHAPTER}

This review of the neural systems that underlie mood disorders is divided into two main sections dealing with (1) the neuroanatomy of the neural circuits that have been implicated in mood disorders, largely taken from studies of non-human primates, and (2) observations on humans, largely taken from clinical studies. The first section begins with a short historical section, on the origin of the idea that emotional behavior is particularly related to what became known as the 'limbic system'. This is followed by consideration of early neuroanatomical work on the limbic system. A more detailed description is then given of circuits that link specific structures that have been implicated in mood disorders, including the ventromedial prefrontal cortex, amygdala, and other limbic structures, ventromedial striatum, and medial thalamus. This description is based primarily on experiments done in the Price lab. Studies in other labs, especially those of Barbas and Petrides, have provided data that are largely consistent with the present description, although that data have not been analyzed in terms of the systems or networks described here.

${ }^{*}$ Correspondence: Dr J Price, Department of Anatomy and Neurobiology, Washington Uninversity School of Medicine, $660 \mathrm{~S}$. Euclid Avenue, Campus Box 8108, St Louis, MO 63110, USA, Tel: + 314362 3587, Fax: +314 747 1150, E-mail: pricej@wustl.edu

Received 6 April 2009; revised 26 June 2009; accepted 16 July 2009

\section{HISTORICAL INTRODUCTION}

In the 1930s and 40s, several observations came together to suggest that there is a system of brain structures that together are responsible for emotion and emotional expression. This became known as the 'limbic system,' based on the 'grand lobe limbique' of Broca (1878). (Limbic refers to an edge or border; in this case it was used to indicate structures around the medial edge of the cerebral hemisphere.) In hindsight, it can be seen that there was considerable initial confusion about the makeup of this system and the role of each of its components, due both to the lack of anatomical and functional data, and to a tendency to over-interpret the limited data that was available. In spite of this the initial framework was adequate to indicate that the system included the hippocampus and amygdala, the anterior and medial thalamus, the cingulate gyrus, and related visceral control areas in the hypothalamus and brainstem. Subsequent work over the last 60 years has provided much more data, and has clarified many of the uncertainties, so that we can now outline the system responsible for emotion in greater detail and nuance. It must be admitted, however, that we are still at an early stage of understanding, and that later generations may look at our misconceptions with the same bemused tolerance as we have for our predecessors.

Emotions are obviously linked to visceral function, and visceral reactions provide the means of emotional expression and possibly even the basis for the emotions 
themselves, as James W (1884) argued. Work by Gaskell, Langley, Cannon and others in the late nineteenth and early twentieth century established that many visceral functions are controlled by the autonomic nervous system, which is itself controlled and coordinated by the hypothalamus, the so-called 'head ganglion of the autonomic nervous system'. Observations on decorticate cats by Bard (1928) and others suggested that the hypothalamus was involved in the production of sham rage, and was responsible for the experience as well as the expression of emotion.

Subsequently, however, many observations indicated that the structures in the cerebral hemispheres are responsible for the generation and experience of emotion, although the hypothalamus and other visceral control structures are responsible for many aspects of emotional expression. Perhaps the most dramatic of these studies were the observations of Kluver and Bucy (1939) on the effect of large temporal lobe lesions in monkeys that included medial temporal structures (amygdala and hippocampus) as well as parts of the lateral temporal cortex. These animals became remarkably docile, and did not show 'normal' fear of such stimuli as human experimenters or snakes. In addition, they did not learn or understand the 'significance' of objects, a deficit that the experimenters referred to as 'psychic blindness'.

These observations were brought together by MacLean (1949), using a model proposed by Papez (1937). Papez and MacLean proposed that the 'Limbic System,' including the hippocampal formation, cingulate gyrus, and anterior thalamus, elaborates emotion and, through its interaction with the hypothalamus, is involved in emotional expression (Figure 1). Subsequently, the hippocampus has been shown to be more involved in memory processing, and the amygdala to be more related to emotion (Zola-Morgan et al, 1991), it should be noted that MacLean included the amygdala in what he referred to as the 'hippocampal formation'. Viewed in the light of the findings from the last 60 years, MacLean's 1949 paper now seems naive and



Figure 1. Drawing of the limbic system centered around the hippocampus (shown as a sea-horse) from the review by MacLean (1949). (HYP= hypothalamus; the circles dorsal to the hypothalamus represent the anterior thalamic nuclei.). flawed, but it was very influential in its time, and it set the stage for much of the subsequent work on the limbic system and the neural basis of emotion.

In the 1950s and 60s, tracing methods based on axonal degeneration began to clarify the connections of the structures of the limbic system. In 1961, Nauta showed in monkeys that the amygdala projects strongly to the hypothalamus, preoptic area, basal forebrain, and the mediodorsal thalamic nucleus. In addition, evidence was obtained for amygdaloid fibers to temporal, insular, and orbital cortical areas, and to the striatum, but these were not considered conclusive. Other experiments (Nauta, 1962; Cowan et al, 1965) indicated that there are also connections between the medial thalamus, orbital cortex, striatum, and hypothalamus, providing the outlines of an interconnected circuit that relates these structures to each other and to the amygdala.

With the advent of tracing methods based on axonal transport, it became possible to define this cortical/ subcortical circuit much more fully. In the 1970s Krettek and Price (1977a, b, c, 1978a,b) used the anterograde transport of $3 \mathrm{H}$-leucine in cats and rats to define projections from the basal and lateral amygdala to the orbital and medial prefrontal, insular, and temporal cortical areas, the mediodorsal thalamic nucleus, and the medial and lateral hypothalamus. Outputs to hypothalamic and brainstem areas involved directly in visceral control were also found, including not just the medial and lateral hypothalamus, but also the periaqueductal gray and the parabrachial nuclei. Subsequent studies with both anterograde and retrograde axonal tracers extended these observations to monkeys (Price and Amaral, 1981; Porrino et al, 1981; Amaral and Price, 1984; Barbas and de Olmos, 1990; Carmichael and Price, 1995a). In addition to confirming the earlier findings, these studies both provided more detail about the cortical areas that received amygdaloid inputs and showed that the fibers, especially from the central and medial amygdaloid nuclei, extend to a variety of visceral control areas from the hypothalamus to the reticular formation and vagal nuclei of the lower medulla. Strikingly, recent studies indicate that there is a high population of GABAergic neurons in the central nucleus, and that many of descending projections to the hypothalamus and brainstem may be inhibitory (McDonald, 2003).

The cortical projections of the amygdala are widespread, but the strongest connections are with the medial prefrontal cortex rostral and ventral to the genu of the corpus callosum. In addition, there are substantial amygdaloid projections to the medial, caudal, and lateral edges of the orbital cortex (leaving the central orbital cortex relatively free), to the rostroventral insula, and to the temporal pole and inferior temporal cortex, extending caudally to the primary visual cortex (V1) (Figure 2, right). There are also amygdaloid interactions with the entorhinal and perirhinal cortex and the hippocampus (subiculum) (Amaral et al, 1992). Recently a projection from the amygdala has been identified to the posterior cingulate cortex (Buckwalter et al, 2008). 
In the striatum, an extensive major amygdaloid projection was shown to the nucleus accumbens, and adjacent medial caudate nucleus and ventral putamen (Russchen et al, 1985). These striatal areas in turn project to the ventral and rostral pallidum, which itself sends GABAergic axons to the mediodorsal thalamic nucleus (MD, Russchen et al, 1987). The perigenual prefrontal cortex is also connected to both the same ventromedial part of the striatum (Haber et al, 1995; Ferry et al, 2000b), and the same region of MD (Russchen et al, 1987; Ray and Price, 1992). This means that there are overlapping and interconnected medial prefrontal cortico-striato-pallidothalamic and amygdalo-striato-pallido-thalamic loops (Figure 2, left). As discussed in later parts of this chapter, these circuits form the core of the neural system that has been implicated in mood disorders.

\section{ORBITAL AND MEDIAL PREFRONTAL CORTEX (OMPFC)}

Since 1995, a series of axonal tracing experiments in macaque monkeys have more completely defined the cortical and subcortical circuits related to the medial prefrontal cortex and amygdala. These observations began with a re-assessment of the architectonic areas in the OMPFC (Carmichael and Price, 1994; Figure 3). Using eight different staining methods, 22 areas were recognized, which provided the basis for a relatively high-resolution analysis of cortical organization. Based on local cortico-cortical connections, two connectional systems or networks were recognized within the OMPFC, which have been referred to as the 'orbital' and 'medial prefrontal networks'. The areas within each network are preferentially interconnected with other areas within the same network, and also have common connections with other parts of the cerebral cortex (Carmichael and Price, 1996; Öngür and Price, 2000; Saleem et al, 2008).

\section{Orbital Prefrontal Network}

The orbital network consists of areas in the central and caudal part of the orbital cortex and the adjacent anterior agranular insular cortex (Figure 3); it does not include areas along the medial edge of the orbital cortex, and two areas in the caudolateral orbital cortex. In addition to the local cortico-cortical interactions between the areas of this network, it is characterized by specific connections with several areas that can be classified as sensory cortex (Figures 4 and 5). These include primary olfactory and
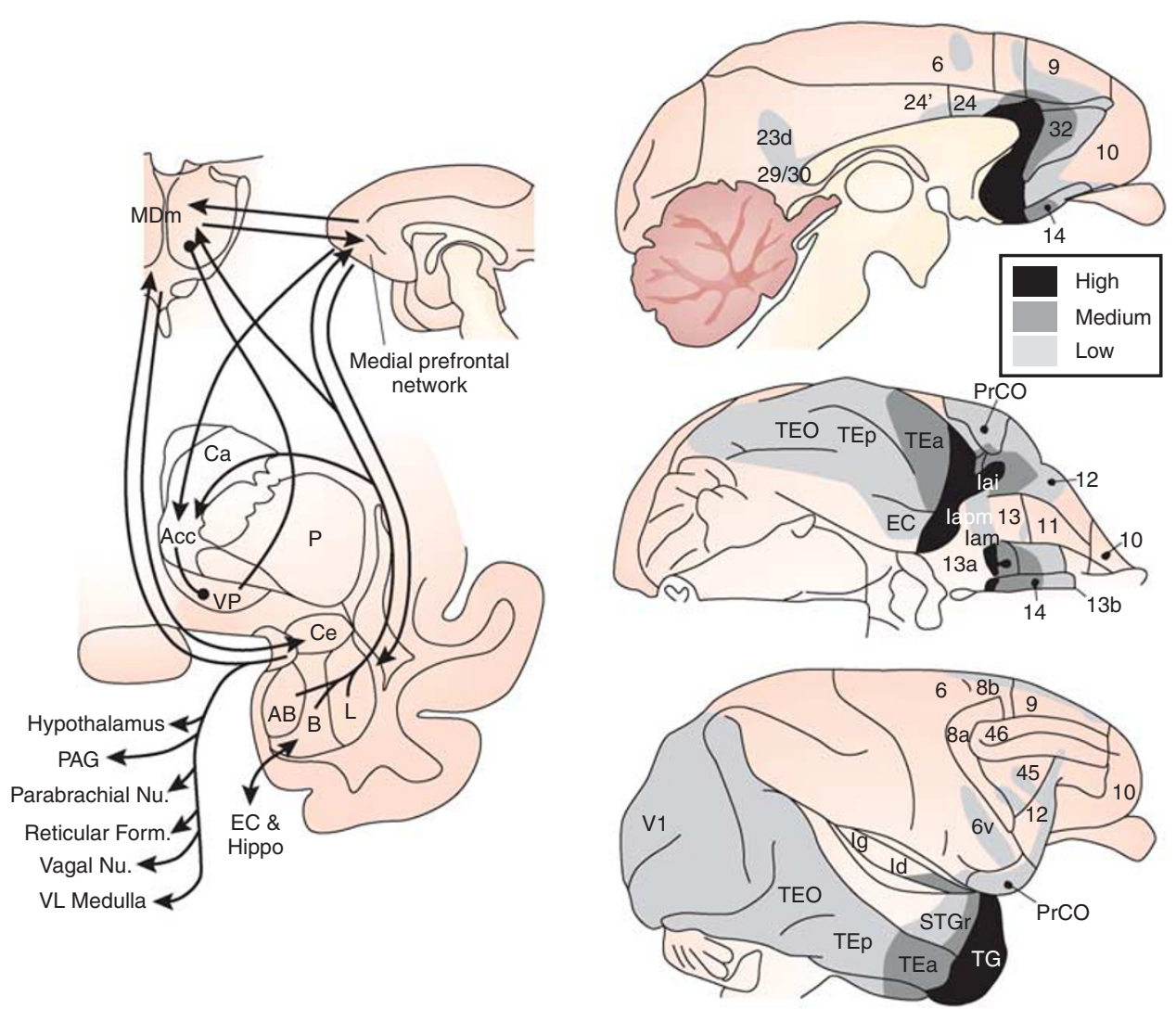

Figure 2. Summary of amygdaloid outputs. Left: diagram of amygdaloid circuits involving the striatum pallidum medial thalamus and prefrontal cortex and output to the hypothalamus and brainstem. Right: diagram of areas of the cerebral cortex that receive axonal projections from the amygdala. The dark, medium, and lightly shaded areas represent high, medium, and low density of amygdaloid fibers. Modified from Amaral et al, 1992. 



Figure 3. The architectonic areas of the OMPFC (above) and LPFC (below) grouped into networks or systems. Areas within each system are preferentially connected with other areas in the same system and have similar connections to other cortical areas. There are also three areas (blue) that are connected to more than one system.

gustatory cortex, visual areas in the inferior temporal cortex (TEa), and the ventral bank of the superior temporal sulcus, somatic sensory areas in the dysgranular insula (Id) and the frontal operculum (Carmichael and Price, 1995b; Saleem et al, 2008). The only sensory modality that apparently lacks an input to the orbital network is audition.

The combination of taste and olfaction underlies the sensation of 'flavor,' and it is notable that the orbital cortex is the first site where taste and olfaction comes together. The further conjunction of flavor with vision and somatic sensation in the orbital network suggests that may particularly provide for integration of food stimuli across modalities.

Remarkably, although recording studies have indeed indicated that neurons in the orbital network areas respond to multi-modal stimuli (eg, the sight, flavor, and texture of food stimuli) the responses reflect affective as well as sensory qualities of the stimuli. For example, responses to food stimuli change with the hunger or satiety of the animal (Rolls, 2000; Pritchard et al, 2008). In addition, many neurons appear to code for the presence or expectation of reward (Schultz et al, 1997), and for the relative value of stimuli (Padoa-Schioppa and Assad, 2006). The orbital network therefore appears to function both as a system for integration of multi-modal stimuli, and as a system for assessment of the value of those stimuli. In addition, lesions of the orbital cortex produce a deficit in the ability to use reward as a guide to behavior (Rudebeck and Murray, 2008), and it is possible that the orbital network also supports abstract assessment of reward.

\section{Medial Prefrontal Network}

The medial network in the OMPFC is probably still more significant for mood disorders. The most prominent amygdaloid and other limbic connections are with areas of the medial network (Carmichael and Price, 1995a; Kondo et al, 2005). It consists of areas on the ventromedial surface of the frontal cortex, rostral and ventral to the genu, areas along the medial edge of the orbital cortex, and a small caudolateral orbital region at the rostral end of the insula (Carmichael and Price, 1996; Figure 3). As with the orbital network, the areas of the medial network are preferentially interconnected with each other, and the network is also characterized by outputs to visceral control areas in the hypothalamus and periaqueductal gray. When the orbital network is to some extent a sensory-related system, therefore, the medial network is more an output system that can modulate visceral function in relation to emotion or other factors.

In addition, the medial network is connected to a very specific set of other cortical regions, particularly the rostral part of the superior temporal gyrus (STGr) and dorsal bank of the superior temporal sulcus (STSd), the anterior and posterior cingulate cortex, and the entorhinal and parahippocampal cortex (Figures 4 and 5; Saleem et al., 2008). This cortico-cortical circuit is very different from, and in some ways complementary to the circuit related to the orbital network. For example, the medial network is primarily connected with the anterior and posterior parts of the cingulate cortex, whereas the orbital network connects primarily to the middle portion of the cingulate (Miller et al, 2008). None of the areas related to the medial network are directly related to a sensory modality. Instead, they together resemble the 'default' system that has been defined by fMRI as areas that are active in a resting state but decrease activity in most tasks (Raichle et al, 2001).

\section{LATERAL PREFRONTAL CORTEX (LPFC)}

Recently, a similar analysis has been made of the organization and connections of the LPFC. This analysis has indicated that large parts of the LPFC are closely related to the medial and orbital prefrontal networks, and may have similar functional roles.

The architectonic subdivisions of the LPFC have been analyzed by Petrides and Pandya (1999), and their map has been used with minor modifications (Figure 3). Petrides and 

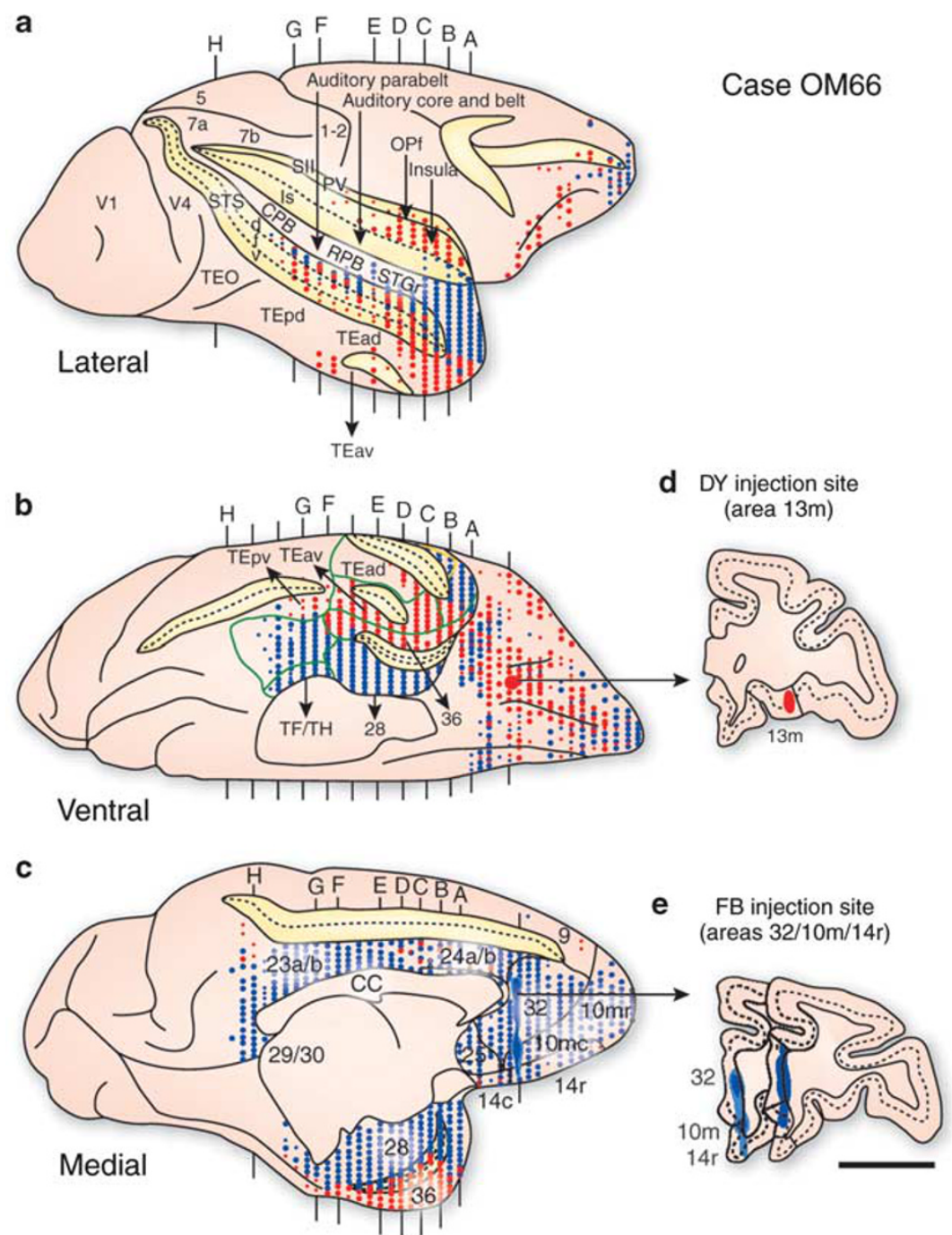

Figure 4. A comparison of the cortico-cortical connections of the 'orbital' and 'medial' prefrontal networks labeled by injections of different retrograde axonal tracers in the same animal. Panels $a, b$, and c illustrate patterns of retrograde neuronal labeling (red and blue dots) on the lateral, ventral, and medial surfaces of the cerebral cortex, related to injections in area $13 \mathrm{~m}$ of the orbital network (in red, panel d) and in areas 32 , $10 \mathrm{~m}$, and $14 \mathrm{r}$ of the medial network (in blue, panel e). From Saleem et al, 2008.

Pandya (1999) also did a number of experiments with injections of axonal tracers in the LPFC. A post hoc analysis of their data suggested that three regions could be distinguished based on local cortico-cortical connections: a dorsal region dorsal to the principal sulcus, a ventral region ventral to the principal sulcus, and a caudal region just rostral to the arcuate sulcus (Price, 2006). Further experiments have confirmed that these regions constitute three separate cortical systems. Each region is preferentially connected to other local areas in the same region, and each is connected to a specific set of areas in other parts of the cortex (Saleem et al, 2008).

\section{Dorsal Prefrontal System}

The dorsal system is interconnected with the medial prefrontal network, and shares most of its other connections (Figure 5). Injections of axonal tracers in these areas dorsal and rostral to the principal sulcus (areas $9,46 \mathrm{~d}$, and part of area 10 at the frontal pole) label connections in other dorsal areas, but not in the ventral or caudal parts of the LPFC, with one exception (area 45a; see section 45a below). As with the medial network, there are outputs from dorsal areas to the hypothalamus and PAG, so this system can also modulate visceral functions. Further, the system connects to the same set of other cortical areas as the medial network, including the rostral superior temporal gyrus, the anterior and posterior cingulate cortex, and the entorhinal and parahippocampal cortex.

\section{Ventral Prefrontal System}

The ventral system of the LPFC consists of areas ventral to the principal sulcus, including area $46 \mathrm{v}, 12 \mathrm{r}$, and $45 \mathrm{~b}$ (area $45 \mathrm{a}$ is a special case, section $45 \mathrm{a}$ see below) (Figure 3). It interacts with the orbital prefrontal network and its 


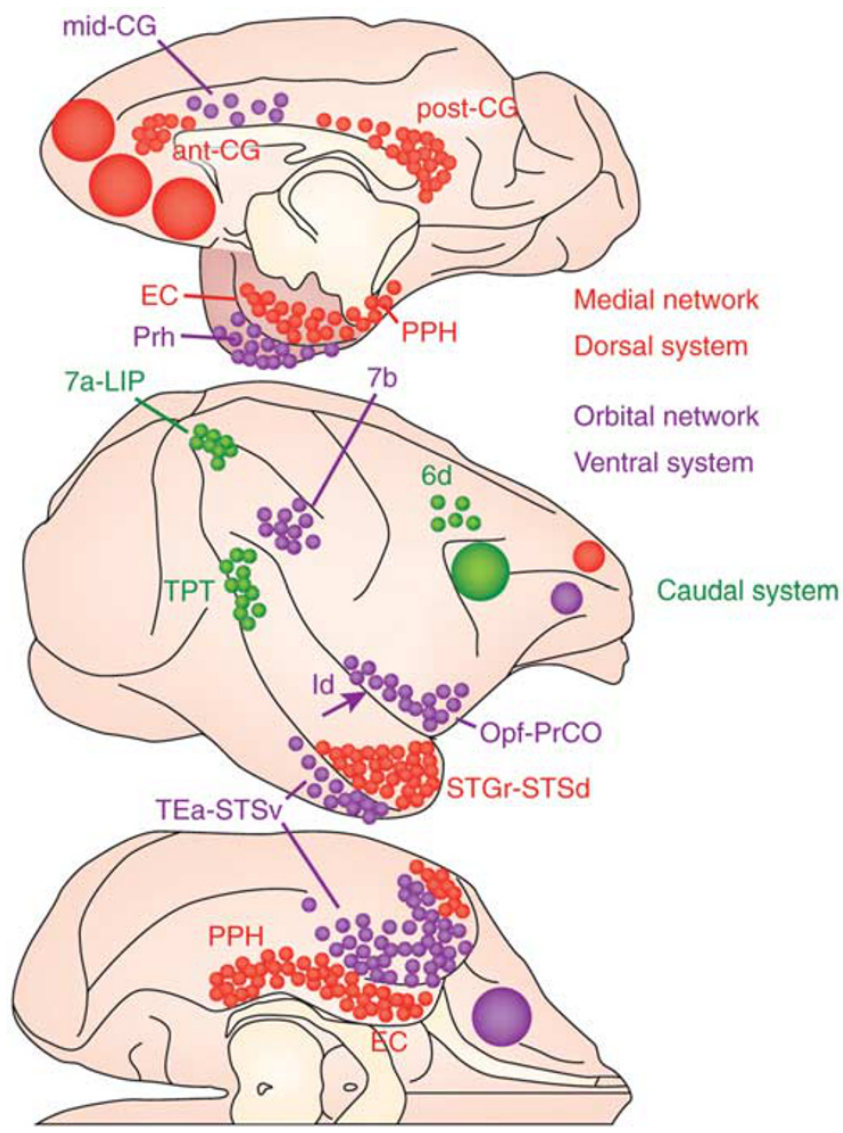

Figure 5. Summary of the major cortico-cortical connections of the systems in the prefrontal cortex that are described in the text.

connections are very similar; indeed area 121 could be considered within either system. As with the orbital network, the principal extrinsic cortical connections are with vision-related areas in the inferior temporal cortex, and somatic sensory-related areas in the dysgranular insula and frontal operculum (Figure 5). The major difference with the orbital network is that there do not appear to be olfactory or taste inputs to the ventral system; it is possible that it functions in the assessment of non-food sensory objects.

\section{Caudal Prefrontal System}

The caudal part of the LPFC is different from the other systems in that it does not relate to either the medial or orbital networks. It includes the frontal eye fields and adjacent cortex (areas 8av, 8ad, and the caudal part of area 46 in the caudal part of the principal sulcus) (Figure 3). The principal cortico-cortical connections of this system are with the dorsal premotor cortex, the posterior part of the dorsal STS (area TPT), and areas LIP and 7a in the posterior parietal cortex (Figure 5). In addition to its role in control of saccadic eye movements, the caudal system may be part of the dorsal attention system (Corbetta et al, 2002).

\section{Area $45 a$}

Area 45a in the caudo-ventral PFC represents an exception to the dorsal, ventral, and caudal systems of the LPFC (Figure 3). Injections of axonal tracers into this area label connections with areas in all parts of the LPFC. The extrinsic cortico-cortical connections resemble those of the dorsal and medial systems, but in label in the superior temporal gyrus extend caudally into the auditory parabelt and belt areas. An interconnected region immediately rostral to $45 \mathrm{a}$ is connected to face-responsive areas in the ventral bank of the STS. Responses to both faces and species-specific auditory stimuli have been recorded in the region of area 45a (Romanski, 2007; Tsao et al, 2008). It is possible that this region represents a multi-modal cortex that also connected to circuits responsible for emotion.

\section{CORTICAL PROJECTIONS TO HYPOTHALAMUS AND BRAINSTEM}

As mentioned above, there are substantial outputs from the medial prefrontal network to the hypothalamus, the periaqueductal gray, and other visceral control centers. (Öngür et al, 1998a,b; An et al, 1998; Rempel-Clower and Barbas 1998; Freedman et al, 2000; Barbas et al, 2003). There is some degree of organization within this system, such that the subgenual cortex provides the heaviest projection, which terminates in both the medial and lateral hypothalamus, and in both dorsolateral and ventrolateral columns of the PAG, while the fibers from the lateral part of the medical network (areas Iai, and 47/12s) are restricted to the lateral hypothalamus, and the ventrolateral PAG (Öngür et al, 1998a, b; An et al, 1998). The origin of this projection extends beyond the medial prefrontal network to include the STGr and STSd, and area 9 in the dorsal prefrontal cortex, both of which are strongly connected to the medial network. Older reports indicate that electrical stimulation of the medial network areas produces disturbances in functions such as heart rate and respiration (Kaada, 1960), and recent fMRI studies have shown that activity in the medial prefrontal cortex correlates with visceral activation in response to emotional (Critchley et al, 2000; Williams et al, 2000) or even non-emotional (Teves et al, 2004) stimuli.

Lesions of the ventromedial prefrontal cortex in humans abolish the normal, automatic visceral response to emotive stimuli (Damasio et al, 1990; Bechara et al, 2000). Strikingly, individuals with these lesions are also severely debilitated in terms of their ability to make appropriate choices, although their cognitive intelligence is intact. Often, they appear to not understand the long-term significance of their actions, and choose in favor of immediate reward without attention to subsequent consequences. The deficit is significant because their lives are severely disrupted by faulty decisions made in business, family relations and other life domains. To account for such deficits, Damasio and his colleagues have proposed the 'somatic marker hypothesis,' which 
supposes that the visceral or bodily reaction that normally accompanies emotion (the somatic marker) serves as a subconscious warning or guide, indicating some behaviors are disadvantageous and should be avoided (Damasio, 1994). The full basis for this effect is probably complex, involving the direct visceral projection and sensation of resulting visceral reactions (eg, sweaty palms, 'butterflies' in the gut, etc.), collateral projections that provide 'as-if circuits, which could give a warning without necessitating sensory awareness, and other circuits such as the corticostriatal-pallidal-thalamic system discussed below. From the viewpoint of mood disorders, over-activation of this system (eg, due to excessive activity in the subgenual cortex, see Neurophysiological Imaging in Major Depressive and Bipolar Disorders below) could produce the chronic sense of 'unease' that is a frequent component of depression.

\section{CORTICO-STRIATAL-THALAMIC CIRCUITS RELATED TO OMPFC}

Like other cortical areas, the prefrontal cortex also has specific connections with the striatum and thalamus. Several circuits can be delineated. The first are the reciprocal thalamo-cortical connections that relay subcortical input to the cortex through principal thalamic nuclei. Closely related to these are the well-known cortico-striato-pallido-thalamic loops, which also involve the principal nuclei. Finally, there are circuits that involve the intralaminar and midline thalamic nuclei, which project to both the striatum and the cortex.

The prefrontal cortex as a whole is reciprocally connected to the mediodorsal thalamic nucleus (MD), with different prefrontal regions related to different portions of $\mathrm{MD}$ (Figure 6). Although the organization of the thalamocortical interconnections are complex, the OMPFC is generally related to medial MD (MDm), whereas the LPFC is related to more lateral parts of MD (Ray and Price, 1993). These parts of MD appear to relay very different types of information to the prefrontal cortex.

\section{Medial Segment of Mediodorsal Thalamic Nucleus}

$\mathrm{MDm}$ receives substantial subcortical inputs from the amygdala, olfactory cortex and other limbic areas (Russchen et al, 1987). Remarkably, all of these areas also send direct (nonthalamic) projections to the OMPFC. In addition to the amygdala, the primary olfactory cortex, the entorhinal, perirhinal, and parahippocampal cortex, and the subiculum all send axonal projections both to the OMPFC Carmichael et al, 1994; Carmichael and Price, 1995a; Kondo et al, 2005), and to medial MD (Russchen et al, 1987). Because of the direct cortical projections, information from the limbic structures does not require a thalamic relay to reach the cortex. Indeed, in most cases the projection to the cortex involves more neurons than that to MD, suggesting that the non-thalamic input to cortex carries more detailed information (Russchen et al, 1987; Carmichael et al, 1994; Price, 2003). It is likely that the trans- thalamic pathway from limbic structures through MDm functions in a different way than the relatively simple relays through other principal thalamic nuclei such as the lateral geniculate nucleus or the ventroposterior nucleus.

In addition to these inputs from limbic structures, which are excitatory and probably glutamatergic, $\mathrm{MDm}$ also receives GABAergic inputs from the ventral pallidum and rostral globus pallidus (Kuroda and Price, 1991a; Churchill et al, 1996), which is part of the cortico-striato-pallido-thalamic loop involving the OMPFC (Figure 6). In MDm, the GABAergic terminals of afferent pallidal fibers synapse on the same dendrites, and occasionally even on the same dendritic spines as the excitatory terminals from the amygdala and other limbic structures (Kuroda and Price, 1991a).

It can be suggested that these convergent but antagonistic inputs would interact to modulate the reciprocal thalamocortical interactions between the OMPFC and MDm. Although the limbic inputs are dominant, ongoing patterns of thalamo-cortical and cortico-thalamic activity would be maintained, allowing for consistent behavior. When pallidal inputs become more prominent, ongoing patterns would be interrupted, allowing a switch from one behavior to another. The affected 'behaviors' would presumably include those that have been associated with the OMPFC: mood, value assessment of objects, and stimulus-reward association. In support of this hypothesis, lesions of the ventral striatum and pallidum, MD, or the OMPFC have been shown to cause perseverative deficits in stimulus-reward reversal tasks in rats and monkeys, such that the animals have difficulty switching away from previously rewarded, but now unrewarded stimuli (Roberts et al, 1990; McBride and Slotnick, 1997; Ferry et al, 2000a; Kazama and Bachevalier, 2009). A similar deficit in subjects with mood disorders might be the difficulty of 'letting go' of a negative mood or mind-set long after the resolution of any traumatic events that might have justified it.

\section{Lateral Segment of Mediodorsal Thalamic Nucleus}

The more lateral parts of MD receive most of their subcortical input from the brainstem, including the superior colliculus and vestibular nuclei, as well as the portions of the reticular formation (Russchen et al, 1987). These inputs are mostly relayed to the frontal eye fields and related areas in the caudal part of the LPFC. In addition, lateral MD receives GABAergic, pallidal-like fibers from the pars reticulata of the substantia nigra (Ilinsky et al, 1985; Kuroda and Price, 1991b). In this case, however, the brainstem areas do not project directly to the cortex, so lateral MD serves as a relay of information to cortex, possibly as well as modulating thalamo-corticothalamic interactions.

\section{Prefrontal Projections to the Striatum}

The OMPFC projects principally to the rostral, ventromedial part of the striatum. The orbital network areas connect to a 

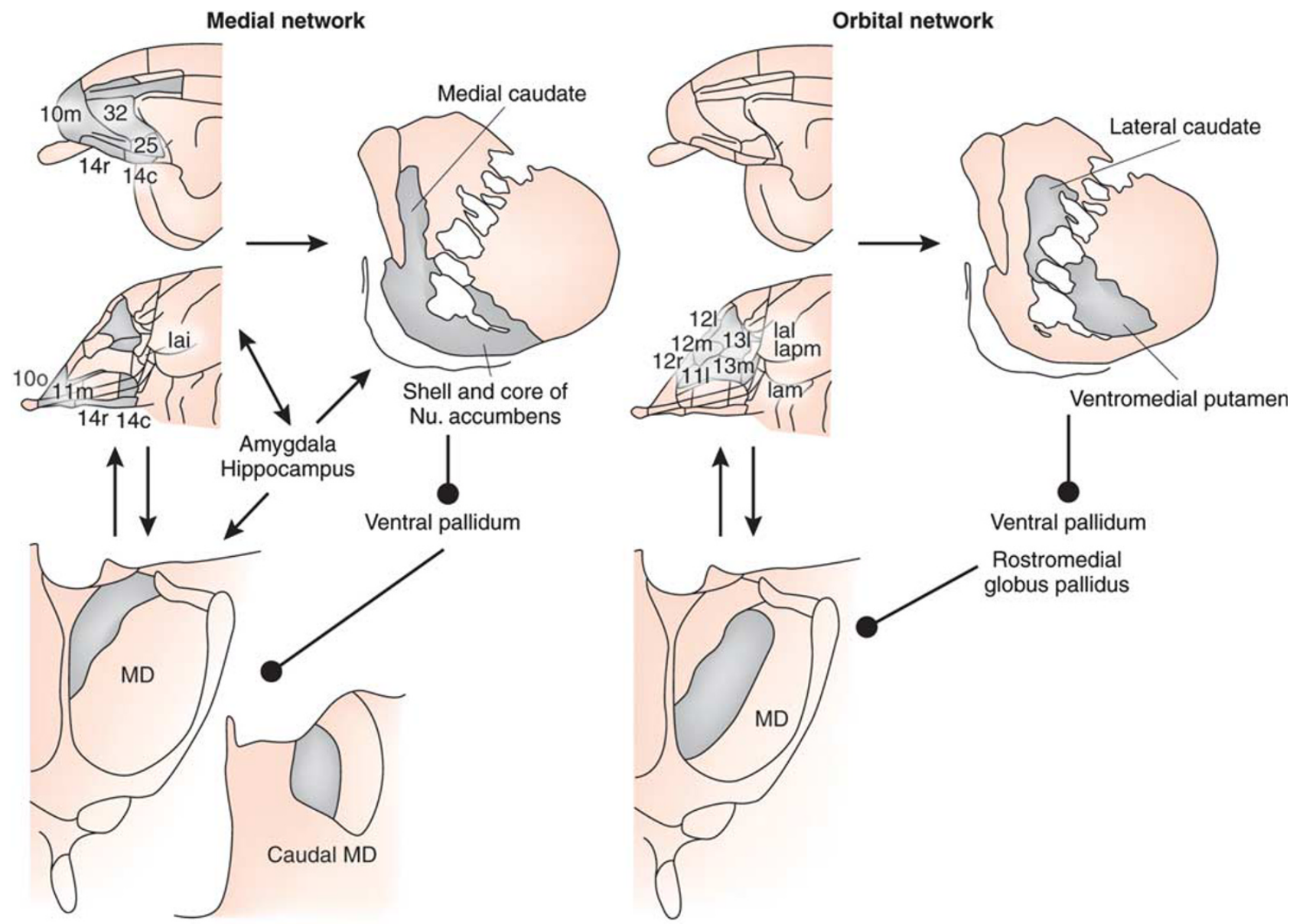

Figure 6. Illustration of the Cortico-Stiato-Pallido-Thalamic loops related to the medial prefrontal network (on left) and the orbital prefrontal network (on right). Note that the two networks are related to parallel but distinct loops that involve adjacent parts of the cortex MD thalamus striatum and pallidum. Limbic structures such as the amygdala and hippocampus are primarily related to the medial network.

relatively central region that spans the internal capsule, and includes parts of both the caudate nucleus and the putamen. Of more significance for mood disorders, however, the medial network areas project to the nucleus accumbens, and the adjacent medial edge of the caudate nucleus bordering the lateral ventricle (Ferry et al, 2000b). Area 25, in the subgenual part of the medial PFC, projects specially to the 'shell' of the nucleus accumbens.

The amygdala input to the striatum is essentially coextensive with that of the medial network. These striatal regions, in turn, project to the ventral pallidum.

The striatal projection from the LPFC as a whole is directed to the central and dorsal part of the striatum (Calzavara et al, 2007). The specific projections from the dorsal, ventral, and caudal parts of the LPFC that were described above have not been clearly defined.

\section{Midline 'Intralaminar' Nuclei of Thalamus}

In addition to the prefrontal connections with $\mathrm{MD}$, there are also important connections with the midline nuclei of the thalamus. These include the paraventricular thalamic nucleus (PVT), as well as other nuclei that extend ventrally on the midline between the anterior and mediodorsal thalamic nuclei. In humans, where the third ventricle is relatively large, they are situated along the sides of the ventricles.

Although they are relatively small, the midline nuclei have remarkably extensive connections (Hsu and Price, 2007, 2009) (Figure 7). They are specifically and reciprocally connected to the medial prefrontal network areas, with little connection to the orbital network. The PVT are connected to the perigenual areas just ventral and rostral to the genu of the corpus callosum. Furthermore, the midline nuclei also have a very substantial projection to the same areas of the ventromedial striatum that receives input from the medial network areas. These nuclei also have important connections with the amygdala, hypothalamus, and brainstem areas, including the periaqueductal gray. Many of the hypothalamic and brainstem inputs to the PVT utilize specific transmitters, including corticosteroid releasing hormone, orexin, serotonin, and norepinephrine (Hsu and Price, 2009). The PVT and other midline thalamic nuclei are therefore situated to relay information about visceral function to both the medial prefrontal network, and the cortico-striato-pallido-thalamic loop that interacts with it. 


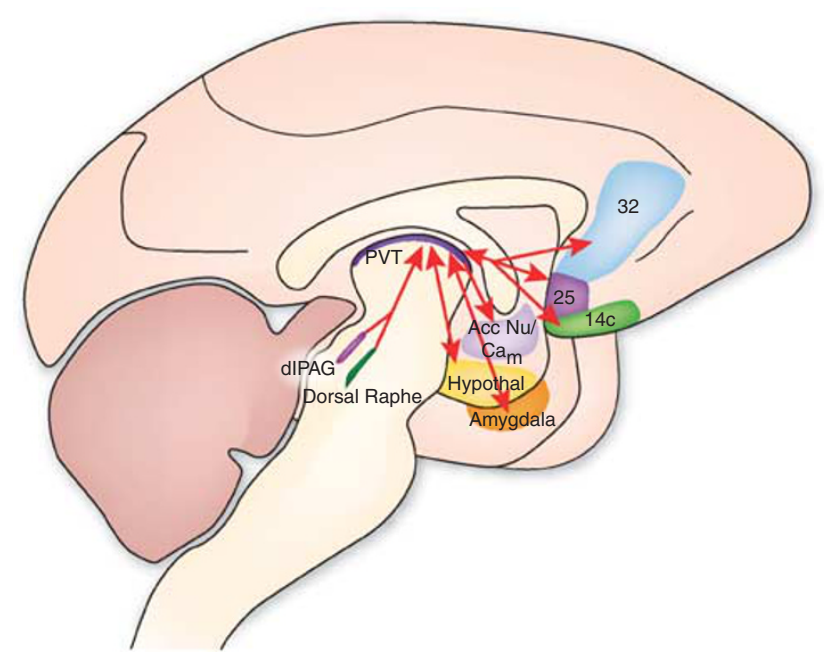

Figure 7. Diagram of connections between the dorsal midline paraventricular nucleus of the thalamus (PVT) with areas of the frontal cortex striatum hypothalamus amygdala and dorsal midbrain.

There is a considerable amount of evidence that links the PVT to the stress response. For example, acute footshock in rats activates paraventricular neurons that project to the medial prefrontal cortex, accumbens nucleus, and the amygdala (Bubser and Deutch, 1999), and lesions of the PVT increase the activation of the central amygdaloid nuclei by an acute stressor (Spencer et al, 2004). Furthermore, it appears that the role of the PVT may be to control the response to chronic stress. Rats subjected to stressors show an acute response, which then habituates when the stressor continues to become chronic. Lesions of the PVT block the habituation to the chronic stress (Bhatnagar et al, 2002), via a mechanism that involves corticosterone action in the PVT (Jaferi and Bhatnagar, 2006). In humans, there is a similar habituation to the neuroendocrine stress response caused by chronic hypoglycemia (Cryer, 2004). Imaging studies show that a circuit including the medial prefrontal cortex and the periaqueductal gray area is activated by acute hypoglycemia (Teves et al, 2004), but that the chronic stage is specifically associated with activity in the midline thalamus (Arbelaez et al, 2008). It is likely that the role of the PVT is general across many types of stressors.

\section{RECENT OBSERVATIONS IN HUMANS WITH MOOD DISORDERS}

Clinical studies of individuals with mood disorders have implicated the networks formed by the OMPFC and anatomically related areas of the striatum, thalamus, temporal cortex, and limbic system reviewed above in the pathophysiology of depression, based upon converging evidence from neuroimaging, neuropathological, and lesion analysis studies. In mood disorder subjects, the medial prefrontal network and related regions have been shown to contain alterations in gray matter volume, cellular elements, neurophysiological activity, receptor pharmacology, and gene expression. Extant neural models of depression posit that dysfunction within the medial network and related limbic structures underlie the disturbances in emotional behavior and other cognitive aspects of the major depressive syndrome. As the medial network and limbic system exert forebrain modulation over visceral responses mediated via the hypothalamus and brainstem, dysfunction within these circuits also may account for the disturbances in autonomic and neuroendocrine function that have been associated with mood disorders. The medial network also is considered part of a larger 'default system' of cortical areas implicated in self-referential functions and the patterns of physiological activity within these areas in depression have been hypothesized to relate to self-absorption or obsessive ruminations accompanying the major depressive syndrome (Raichle et al, 2001; Gusnard et al, 2001; Drevets et al, 2002a; Grimm et al, 2009). These hypotheses are compatible with treatments for depression, involving pharmacological, neurosurgical, and deep brain stimulation methods, that appear to suppress pathological activity within components of extended medial prefrontal network such as the subgenual anterior cingulate cortex (sgACC), ventromedial frontal polar cortex, ventromedial striatum, and amygdala (Drevets et al, 2002a; Mayberg et al, 2005; Drevets and Price, 2005; Van Laere et al, 2006). The ensuing sections discuss the abnormalities identified in the primary mood disorders (major depressive disorder (MDD) and bipolar disorder (BD)) in the context of the extended medial prefrontal network.

\section{Neuroimaging Abnormalities in Mood Disorders}

Although MDD and BD constitute the first and fifth leading causes of years lived with disability, respectively (WHO, 2001), little is known about their pathogenesis. As these conditions are not associated with gross brain pathology, or with clear animal models for spontaneous recurrent mood episodes, the development of tools that allowed noninvasive assessment of human brain structure and function has proven critical to elucidating their neurobiology. Thus, the development of neuroimaging methods for in vivo characterization of the anatomical, physiological, and neurochemical correlates of mood disorders has enabled significant advances toward elucidating their pathophysiology.

The best studied component of MDD and BD has been the major depressive episode (MDE). The clinical phenomenology of MDE implicates brain systems involved in the regulation of mood, anxiety, fear (eg, phobias, panic attacks, and post-traumatic stress syndromes commonly occur comorbidly with depression), reward processing, attention, motivation, stress responses, social cognition, and neurovegetative function (ie, sleep, appetite, energy, libido) (APA, 1994; Kessler et al, 2005). In BD, episodes of depression occur alternately with manic or hypomanic episodes during which the mood becomes euphoric and labile, the capacity for deriving pleasure increases, behaviors aimed at deriving 
pleasure increase, and energy psychomotor activity, libido, and self esteem become elevated. Thus, the same domains are implicated in depression and mania, although the characteristic disturbance in emotional behavior within these syndromes appears opposite with respect to emotional valence. Thus the clinical manifestations of mood disorders would appear to implicate the cognitive, emotional and visceral functions subserved by the orbital and medial prefrontal networks.

The neuroimaging abnormalities found in MDD and BD generally have corroborated hypotheses regarding the neural circuitry underlying depression that initially were based on observations from the behavioral effects of lesions experimentally placed in experimental animals (see 'Cortico-Striatal-Thalamic Circuits Related to the OMPFC' above) as well as from the clinical manifestations of lesions or atrophy arising in the context of neurological disorders associated with MDE. In particular, it had been observed that degenerative basal ganglia diseases, and lesions of the striatum and OMPFC, increased the risk of developing MDE (Folstein et al, 1985). These data implicated the limbic-cortico-striato-pallido-thalamic circuits related to the medial and orbital prefrontal networks (Figure 6). Because these neurological disorders affect synaptic transmission through the cortico-striato-pallidothalamic circuitry in diverse ways it appears that dysfunction that alters transmission through these circuits in a variety of ways can produce the pathological emotional symptoms encompassed by the MDE criteria (Drevets et al, 2004a).

\section{Brain Structural Abnormalities in Mood Disorders}

Patients with mood disorders manifest abnormalities of morphology or morphometry in several medial prefrontal network and limbic structures (Drevets and Price, 2005a). The anatomical specificity of these findings is attested to by the lack of difference in whole brain volume between samples with early-onset mood disorders and age-matched healthy control samples. The magnitude or prevalence of these abnormalities depends to some extent on clinical characteristics such as age-at illness-onset, capacity for developing mania or psychosis, and evidence for familial aggregation of illness. For example early-onset nonpsychotic MDD and BD cases also consistently show volumetric abnormalities that appear localized to structures within the extended medial prefrontal network (Table 1). In contrast, elderly MDD subjects with late-onset depression show a higher prevalence of neuroimaging correlates of cerebrovascular disease relative both to age-matched healthy controls and to elderly depressives with an early age at depression-onset (reviewed in Drevets et al, 2004a). Similarly, MDD and BD cases that have either delusions or late-life illness-onset show nonspecific signs of atrophy, such as lateral ventricle enlargement, that are absent in early-onset non-psychotic MDD cases. Nevertheless, such cases have been differentiated from relevant control groups on the basis of lesions or gray matter loss within the OMPFC (MacFall et al, 2001; Coryell et al, 2005).

The most prominent volumetric abnormality reported to date in MDD and BD has been a reduction in gray matter in the left anterior cingulate cortex (ACC) ventral to the

Table 1 Neuroimaging and Histopathological Abnormalities Evident in the Visceromotor Network (Öngür et al, 2003) in Early-Onset, Recurrent Major Depressive Disorder and/or Bipolar Disorder

Brain region

Gray matter volume

Cell counts, cell markers

Glucose metabolism, CBF

Dep vs Con

Dep vs Con

Dep vs Con

Dep vs Rem

\begin{tabular}{|c|c|c|c|c|}
\hline Dorsal medial/anterolateral PFC (BA9) & $\downarrow$ & $\downarrow$ & $\downarrow$ & $\uparrow$ \\
\hline Frontal polar C (BA |O) & & $\downarrow$ & $\uparrow$ & $\uparrow$ \\
\hline Subgenual anterior cingulate $C$ & $\downarrow$ & $\downarrow$ & $\downarrow / \uparrow^{a}$ & $\uparrow$ \\
\hline Pregenual anterior cingulate $\mathrm{C}$ & $\downarrow$ & $\downarrow$ & $\uparrow$ & $\uparrow$ \\
\hline Orbital C/ventrolateral PFC & $\downarrow$ & $\downarrow$ & $\uparrow$ & $\uparrow$ \\
\hline Posterior cingulate & $\downarrow$ & & $\uparrow$ & $\uparrow$ \\
\hline Parahippocampal C & $\downarrow$ & $\downarrow B D$ & $\uparrow$ & $\uparrow$ \\
\hline Amygdala & $\downarrow / \uparrow^{b}$ & $\downarrow \mathrm{MDD}$ & $\uparrow$ & $\uparrow$ \\
\hline Ventromedial striatum & $\downarrow$ & & $\uparrow$ & $\uparrow$ \\
\hline Hippocampus & $\downarrow$ & $\downarrow \mathrm{BD}$ & n.s. & n.s \\
\hline Superior temporal G/temporopolar C & $\downarrow$ & & & $\uparrow$ \\
\hline Medial thalamus & & & $\uparrow$ & $\uparrow$ \\
\hline
\end{tabular}

Abbreviations: C, cortex; Dep vs Con, unmedicated depressives vs healthy controls; Dep vs Rem, unmedicated depressives vs themselves in either the medicated or unmedicated remitted phases; G, gyrus; NS, differences generally not significant; PFC, prefrontal cortex.

${ }^{a}$ In the subgenual anterior cingulate cortex the apparent reduction in CBF and metabolism in PET images of depressed subjects is thought to be accounted for by the reduction in tissue volume in the corresponding cortex, as after partial volume correction for the reduction in gray matter the metabolism appears increased relative to controls.

${ }^{\mathrm{b}}$ The literature is in disagreement with respect to the amygdala volume in mood disorders. In BD, volume appears reduced in unmedicated subjects but enlarged in subjects medicated with mood stabilizers known to exert neurotrophic/ neuroprotective effects in rodents.

Empty cells indicate insufficient data. Modified from (Drevets, 2007). 
corpus callosum genu (ie, 'subgenual'; Figure 8) (Botteron et al, 2002; Coryell et al, 2005; Drevets et al, 1997; Hirayasu et al, 1999; Koo et al, 2008). These studies have implicated subgenual PFC regions of the infralimbic cortex (BA 25) (eg, Coryell et al, 2005) and the adjacent sgACC corresponding to BA 24sg (eg, Öngür et al, 1998a, b, 2003; Drevets et al, 1997a) (Figure 9). The extant data suggest this volumetric reduction exists early in illness and in young adults at high familial risk for MDD (Botteron et al, 2002; Hirayasu et al, 1999; Drevets et al, 2004b; Boes et al, 2008). Nevertheless, a longitudinal study also has shown progression of the abnormality in subjects with psychotic mood disorders (Koo et al, 2008). The volumetric deficit applies to males (Hastings et al, 2004; Boes et al, 2008) and females (Botteron et al, 2002), to psychotic unipolar and bipolar depression (Hirayasu et al, 1999; Coryell et al, 2005; Adler et al, 2007), and to bipolar-spectrum illness (Haznedar et al, 2005). In MDD the reduction in sgACC volume persists despite successful treatment with antidepressant drugs (Drevets et al, 1997a). However, chronic lithium treatment which exerts robust neurotrophic effects in animal models has been associated with increasing gray matter volume toward normal in treatment responders in the sgACC and other PFC areas (Moore et al, 2009; Drevets et al, 2008).

The abnormal reduction in sgACC volume primarily has been identified in mood-disordered subjects with evidence for familial aggregation of illness. One study showed that the mean sgACC gray matter volume was reduced significantly $v s$ controls in subjects with psychotic affective illness who also had mood-disordered first-degree relatives but not in subjects without mood-disordered first-degree relatives (Hirayasu et al, 1999). Similarly, McDonald et al (2004) showed that reduced volume of the right 'perigenual' ACC region (including both the sgACC and the 'pregenual' ACC (pgACC) anterior to the corpus callosum); was associated with increasing genetic risk for BD (based upon numbers of affected relatives). It has also been reported that the left perigenulate ACC volume was smaller in boys with subclinical depressive symptoms, and that the negative correlation between left sgACC volume and depression symptoms was particularly robust in boys with a family history of depression (Boes et al, 2008). Notably, the short allele of the serotonin transporter promoter region length polymorphism (5HTT-PRL) has been identified as a genetic factor that is associated with both an increased vulnerability for developing MDD within the context of stress (Caspi et $a l, 2003)$ and a reduction in sgACC gray matter volume (Pezawas et al, 2005).

Gray matter volume is also reduced in the orbitofrontal cortex (BA 11,47) in both MDD and $\mathrm{BD}$, in the ventrolateral PFC (VLPFC; BA 45), frontal polar/dorsal anterolateral PFC (BA 9,10), parahippocampal gyrus and temporopolar cortex


Figure 8. Areas of abnormally increased physiological activity in familial MDD shown in images of unpaired t-values, computed to compare activity between depressives and controls (Drevets et al, 1992, 1997a). Upper left: positive $t$-values in a sagittal section located $17 \mathrm{~mm}$ left of midline $(X=-17)$ show areas where CBF is increased in depressives vs controls in the amygdala and medial (MED) orbital cortex (reproduced from Price et al, 1996). Upper right: positive $t$-values in a sagittal section $41 \mathrm{~mm}$ left of midline $(X=-41)$ show areas where CBF is increased in depressives in the left ventrolateral PFC (VLPFC) areas corresponding approximately to the intrasulcal portion of BA 47 (area 47/12s) and to BA 45a (reproduced from Drevets et al, 2004a). Lower right: positive $t$-values in a coronal section located $19 \mathrm{~mm}$ posterior to the anterior commissure $(Y=-19)$ shows an area where $C B F$ is increased in depressives in the left medial thalamus (from Drevets and Todd, 2005b). Lower left: coronal (31 mm anterior to the anterior commissure; $Y=31$ ) and sagittal ( $3 \mathrm{~mm}$ left of midline; $X=-3$ ) sections showing negative voxel $t$-values in which metabolism is decreased in depressives vs controls. The reduction in prefrontal cortex (PFC) activity localized to in the anterior cingulate gyrus ventral to the genu of the corpus callosum (ie, subgenual) (Table 1; reproduced from Drevets et al, 1997a). Anterior or left is to left. 




$10 \mathrm{~mm}$

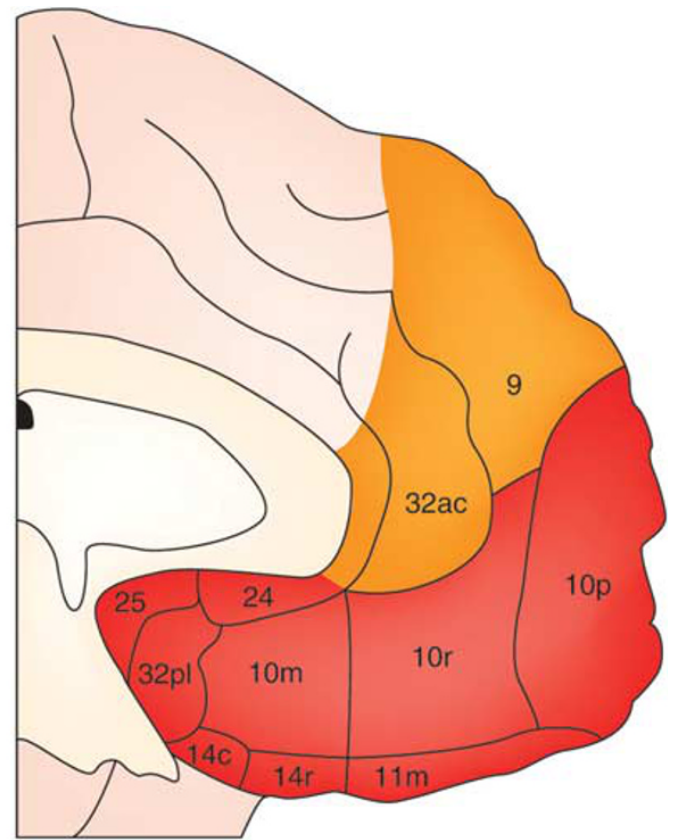

Figure 9. The cytoarchitectonic subdivisions of the human medial prefrontal (right) and orbital (left) cortex surfaces are distinguished here as being predominantly in the medial (red) and orbital (yellow) prefrontal networks. The orange areas are part of the dorsal prefrontal system. Modified from Öngür et al, 2003.

in MDD, and in the posterior cingulate cortex and superior temporal gyrus in BD (Drevets and Price, 2005a; Lyoo et al, 2004; Drevets et al, 2004a; Nugent et al, 2006; Bowen et al, $1989)$. In BD the peak reduction in gray matter in the lateral OFC localized to the sulcal BA47 cortex (Nugent et al, 2006) implicating the putative human homolog of Area 120 described above as being anatomically related to both the medial and the orbital prefrontal networks (Figures 3 and 8). Similarly, in MDD gray matter was reduced in BA 45 (Bowen et al, 1989), highlighted above as sharing connectivity with both the medial and orbital networks (Figures 3 and 8).

Some studies also reported reductions in hippocampal volume in MDD ranging in magnitude from 8 to $19 \%$ although other studies did not replicate these differences (reviewed in Drevets, 2004). The discrepant results across studies may reflect clinical heterogeneity, as one study reported that reduced hippocampal volume was limited to depressed women who suffered early-life trauma (Vythilingam et al, 2002), whereas others reported that hippocampal volume correlated inversely with time spent depressed (eg, Sheline et al, 2003). The reduction in hippocampal volume persists during symptom remission (Neumeister et al, 2005).

In the amygdala the volume has been reported to be increased in some studies but decreased in others in depressives relative to controls (reviewed in Drevets et al, 2004a). Nevertheless, using higher resolution vMRI data, Savitz et al (2009) recently showed that the amygdala volume is abnormally smaller in unmedicated BD subjects, but larger in $\mathrm{BD}$ subjects receiving mood-stabilizing treatments that exert neurotrophic effects in experimental animals.
In the striatum Husain et al (1991) reported that the putamen was smaller in depressives than controls, and Krishnan et al (1992) found a smaller caudate nucleus volume in depressives than controls. In a sample limited to elderly depressives Krishnan et al (1993) also reported smaller putamen and caudate volumes relative to controls. These findings were consistent with the postmortem study of Baumann et al (1999), which found that caudate and accumbens area volumes were decreased in both MDD and BD samples relative to control samples. Nevertheless, other studies found no significant difference in striatal or pallidal volumes between younger MDD subjects and controls (reviewed in Drevets et al, 2004a).

Finally, consistent with evidence that the hypothalamicpituitary-adrenal (HPA) axis function is elevated in some mood-disordered subgroups, the pituitary and adrenal glands appear enlarged in MDD (Krishnan et al, 1991; Drevets et al, 2004a). These changes putatively reflect elevated stimulation of the pituitary by CRH and of the adrenal cortex by ACTH. Depressed subjects show blunted $\mathrm{ACTH}$ responses to $\mathrm{CRF}$ in vivo, reduced CRF receptor density in the PFC, and increased corticotrophic cell size and mRNA levels in the pituitary postmortem, indicating chronic activation of the HPA axis (Gold and Chrousos, 2002; Lopez et al, 1992; Swaab et al, 2005).

\section{Neurophysiological Imaging in Major Depressive and Bipolar Disorders}

Many of the regions in which structural abnormalities are evident in mood disorders also contain abnormalities of blood flow and glucose metabolism (Table 1; Figure 8). In most of these structures, and particularly those that form 
the extended visceromotor network, the metabolic activity measured under resting conditions appears increased in the depressed phase relative to the remitted phase of MDD. This pattern of differences were shown by longitudinal studies of depressed patients imaged before $v s$ after treatment (eg, Drevets et al, 2002a), and of remitted patients scanned before $v s$ during depressive relapse (eg, Neumeister et al, 2004; Hasler et al, 2008).

Nevertheless, the reduction in gray matter volume in some structures appears sufficiently prominent to produce partial volume effects in functional brain images due to their relatively low spatial resolution yielding complex relationships between physiological measures and depression severity. For example, relative to controls depressed MDD and BD subjects show metabolic activity that appears reduced in the sgACC (Figure 8) (Drevets et al, 1997a, 2002a; Liotti et al, 2002; Ketter et al, 2001; Kegeles et al, 2003; Kruger et al, 2003; Pizzagalli et al, 2004). These metabolic reductions may predate the onset of clinical symptoms as (Kumano et al, 2006) found that cancer patients who went on to develop depression had lower baseline metabolic rates of the sgACC compared with cancer controls who did not become depressed. However, other studies reported increased metabolic activity in the sgACC in primary (Wu et al, 1999; Mayberg et al, 2000, 2005; Dunn et al, 2002; Bauer et al, 2005; Clark et al, 2006; Kumano et al, 2006; Mah et al, 2007) or secondary depression (Inagaki et al, 2007). These apparently discrepant results may be explained by the inter-relationships between deficits in gray matter volume and physiological imaging data obtained using low resolution instruments.

In MDD and BD samples who have abnormal reductions of both gray matter volume and metabolism of the sgACC (Drevets et al, 1997a), correction of the metabolic data for the partial volume averaging effect because of the volumetric deficit indicated that metabolism was actually increased in the sgACC in the unmedicated-depressed phase (Drevets and Price, 2005a). Consistent with this conclusion, sgACC metabolism appears elevated in the depressed phase $v s$ the remitted phase of the same MDD subjects. For example in remitted MDD subjects the sgACC metabolism increases during depressive relapse induced during either tryptophan (Neumeister et al, 2004) or catecholamine depletion (Hasler et al, 2008). Conversely, the sgACC metabolism decreased during symptom remission induced by antidepressant drugs (Drevets et al, 1997a, 2002a; Holthoff et al, 2004; Mayberg et al, 2000) electroconvulsive therapy (Nobler et al, 2001) or deep brain stimulation (Mayberg et al, 2005). Several studies also found that depression severity in MDD correlates positively with metabolism in the sgACC (eg, Osuch et al, 2000), and in healthy humans blood flow increases in the sgACC during experimentally induced sadness (George et al, 1995; Mayberg et al, 1999). Finally, in depressed BD subjects medicated chronically with lithium which results in increased gray matter volume in the prefrontal cortex of lithium-responsive $\mathrm{BD}$ subjects to an extent that would reduce or eliminate partial volume effects (Moore et al, 2008; Drevets et al, 2008) the sgACC metabolism appears abnormally elevated relative to healthy controls (Mah et al, 2007; Bauer et al, 2005).

Hemodynamic activity increases in the perigenual ACC during a variety of emotional-behavioral tasks including tasks involving sadness induction (George et al, 1995; Mayberg et al, 1999) exposure to traumatic reminders (reviewed in Rauch and Drevets, 2007) selecting sad or happy targets in an emotional go-no go study (Elliott $e t$ al, 2000); monitoring of internal states in individuals with attachment-avoidant personality styles (Gillath et al, 2005) and extinction learning to previously fear-conditioned stimuli (Phelps et al, 2004). These findings suggest that in humans the perigenual ACC has roles in the automatic regulation of emotional behavior. In contrast, more dorsal regions of the pgACC show physiological responses to more diverse types of emotionally valenced or autonomically arousing stimuli (Drevets and Raichle, 1998; Bush et al, 2000; Critchley et al, 2003). Notably, higher activity in the pgACC holds positive prognostic significance in MDD, as depressives who improve during antidepressant treatment show higher pgACC metabolism and electrophysiological activity before treatment than treatment-nonresponsive cases or healthy controls (Mayberg et al, 1997; Pizzagalli et al, 2001).

Although the pattern of activity in the extended visceromotor network generally is one in which metabolism is elevated during the depressed relative to the remitted phases, the relationship between activity and symptom severity differs in valence across structures. This is compatable with preclinical evidence that distinct medial prefrontal network structures are involved in opponent processes with respect to emotional behavior (VidalGonzalez et al, 2006). Regions where metabolism correlates positively with depression severity include the amygdala, anterior sgACC, and ventromedial frontal polar cortex (Drevets and Price, 2005a). Reduction in metabolism and blood flow in these regions with recovery is found with both antidepressant drug treatment and deep brain stimulation of the sgACC or anterior capsule (Mayberg et al, 1999, 2005; Drevets et al, 2002a; Van Laere et al, 2006), despite the diverse mechanisms underlying these treatments. Conversely, recovered MDD patients who experience depressive relapse under experimental conditions involving catecholamine or serotonin depletion show increases in metabolic activity in the sgACC and ventromedial frontal polar cortex as depressive symptoms return (Neumeister et al, 2004; Hasler et al, 2008). Left amygdala activity also increased during tryptophan depletion-induced relapse, but only in MDD patients who were homozygous for the long allele of the 5HTT-PRL polymorphism (Neumeister et al, 2006b).

In a similar manner, some other abnormalities in physiological activity in the amygdala and other structures appear specific to clinically defined subtypes of mood 
disorders. For example, in the amygdala, resting metabolism was elevated in subjects classified as BD-depressed, familial pure depressive disease (FPDD), melancholic subtype, or responsive to a night of total sleep deprivation (reviewed in Drevets, 2001; Drevets et al, 2004a). However, other MDD subgroups have not shown elevated resting metabolic activity in the amygdala, raising the possibility this abnormality is associated with specific illness subtypes or manifestations such as cortisol hypersecretion (Drevets et al, 2002a).

A broader range of depressed subjects shows abnormal hemodynamic responses in the amygdala to specific types of emotional stimuli. In MDD subjects the amygdala shows exaggerated hemodynamic responses during exposure to sad words (Siegle et al, 2002), explicitly presented sad faces (Drevets et al, 2001; Fu et al, 2004), masked fearful faces (Sheline et al, 2001), and masked sad faces (Fu et al, 2004). Similar increases in amygdala activity in response to sad faces were observed in remitted subjects with MDD (Neumeister et al, 2006a) suggesting that this abnormality is trait-like in MDD. In another study, healthy volunteers showed a linear increase in activity bilaterally in fusiform cortex and ventral striatum as the intensity of a happy facial expression was increased, whereas MDD patents showed a similar response pattern as the intensity of a sad expression was increased, although this pattern extended into hippocampus and amygdala (Surguladze et al, 2005). These data suggest that neural responses within the circuits underlying emotional processing are altered in a way that reflects the emotional processing bias observed in neuropsychological studies of mood disorders.

Depressed patients manifest a mood-congruent processing bias in which stimulus processing is preferentially directed towards negative information (Elliott et al, 2000; Murphy et al, 1999; Murray et al, 1999). Thus, currently depressed patients show enhanced recall for negatively $v s$ positively valenced information on memory tests (Bradley et al, 1995; Murray et al, 1999), greater interference from depressionrelated negative words $v s$ happy or neutral words on emotional stroop tasks (Broomfield et al, 2007; GallardoPerez et al, 1999), faster responses to sad $v s$ happy words on affective attention shifting tasks (Murphy et al, 1999; Erickson et al, 2005), and preferential attentiveness to faces with sad vs neutral expressions on a face dot-probe task (Gotlib et al, 2004a, b). Depressed patients also are more negative in their interpretation of ambiguous words (Mogg et al, 2006) and ambiguous situations (Nunn et al, 1997) than controls. These findings suggest that a bias in stimulus processing exists in depression that may produce a preferential representation of negatively toned information. Within the context of aversive $v s$ appetitive conditioning studies of MDD this bias was associated with an altered pattern of hemodynamic activity in prefrontal cortical components of the orbital network (MatinSoelch and Drevets WC, unpublished data), highlighted above for its role in assessing the relative value of sensory stimuli within the context of motivation.
Finally, during $\mathrm{MDD}$, or the depressed phase of $\mathrm{BD}$, glucose metabolism in the accumbens, medial thalamus, and posterior cingulate cortex is abnormally elevated and hemodynamic responses to rewarding or emotional stimuli are altered (Drevets et al, 2002a, 2004a). For example, in fMRI studies the regional hemodynamic responses are attenuated in the ventral striatum in reward-processing tasks and in both the ventral striatum and the posterior cingulate in tasks involving negative feedback (eg, Knutson et al, 2008; Taylor-Tavares et al, 2008).

\section{NEUROPATHOLOGICAL CORRELATIONS WITH NEUROIMAGING ABNORMALITIES}

The structural imaging abnormalities observed in mood disorders discussed above have been associated with histopathological abnormalities in postmortem studies of MDD and/or BD. Such studies have reported reductions of gray matter volume thickness or wet weight in the sgACC, posterior orbital cortex, and ventral striatum (Baumann et al, 1999; Bowen et al, 1989; Öngür et al, 1998a,b; Rajkowska et al, 1999), and greater decrements in volume following fixation (implying a deficit in neuropil) in the hippocampus (Stockmeier et al, 2004) in MDD and/or BD subjects relative to controls. The histopathological correlates of these abnormalities included reductions in glia with no equivalent loss of neurons reductions in synapses or synaptic protein elevations in neuronal density and reductions in neuronal size in MDD and/or BD samples (Rajkowska et al, 1999; Öngür et al, 1998a,b; Cotter et al, 2001a, 2002; Eastwood and Harrison, 2000, 2001; Uranova et al, 2004). Reductions in glial cell counts and density, and/ or glia-to-neuron ratios additionally also have been found in MDD subjects $v s$ controls in the pgACC (Cotter et al, 2001a), dorsal anterolateral PFC (BA9) (Cotter et al, 2002; Uranova et al, 2004), and amygdala (Bowley et al, 2002; Hamidi et al, 2004). Finally, the mean size of neurons was abnormally reduced in the dorsal anterolateral PFC (BA 9) in MDD (Rajkowska et al, 1999), and the density of nonpyramidal neurons was decreased in the ACC and hippocampus in BD (Benes et al, 2001; Todtenkopf et al, 2005) and in the dorsal anterolateral PFC (BA9) in MDD (Rajkowska et al, 2007). Reductions in synapses and synaptic proteins were evident in $\mathrm{BD}$ subjects in the hippocampal subiculum/ventral CA1 region (Eastwood and Harrison, 2000; Rosoklija et al, 2000), and the expression of multiple genes involved in axonal growth/ synaptic function was reduced in MDD subjects in the middle temporal cortex (Aston et al, 2005). In several studies, these deficits largely were accounted for by differences in the left hemisphere (eg, Bowley et al, 2002; Hamidi et al, 2004; Bowen et al, 1989; Öngür et al, 1998a, b).

The glial cell type implicated most consistently in mood disorders has been the oligodendrocyte (eg, Uranova et al, 2004; Hamidi et al, 2004). The reduction in oligodendrocytes conceivably may arise secondary to an effect 
on myelin, either through demyelination, abnormal development, or atrophy in the number of myelinated axons. Notably, myelin-basic protein concentration was decreased in the frontal polar cortex (BA 10) (Honer et al, 1999), and the expression of genes related to myelinating oligodendrocyte function was decreased in the middle temporal gyrus in MDD subjects relative to controls (Aston et al, 2005). Compatible with these data myelin staining was decreased in the deep white matter of the dorsolateral PFC in MDD and BD subjects (Regenold et al, 2007), and the white matter volume of the genual and splenial portions of the corpus callosum were abnormally reduced in MDD and BD (eg, Brambilla et al, 2004; Martinez et al, 2002). In several reports, the deficits in glia in the cerebral cortex depended upon laminar analysis with the greatest effects in layers III, V, and VI (Cotter et al, 2001a, 2002; Rajkowska et al, 1999, 2001; Uranova et al, 2004; Vostrikov et al, 2007). This is compatible with the hypothesis that myelinating oligodendrocyte function is reduced in MDD because these layers contain the intracortical plexuses of myelinated fibers (bands of Baillarger, layers III and V), or a large component of myelinated fibers running between the gray and white matter (layer VI).

Satellite (perineuronal) oligodendrocytes also were implicated in mood disorders by an electron microscopic study of the PFC in $\mathrm{BD}$, which revealed decreased nuclear size clumping of chromatin and indications of both apoptotic and necrotic degeneration in these cells (Uranova et al, 2001; Vostrikov et al, 2007). Satellite oligodendrocytes are immunohistochemically reactive for glutamine synthetase, suggesting they function like astrocytes to take up synaptically released glutamate for conversion to glutamine and cycling back into neurons (D'Amelio et al, 1990).

Reductions in astroglia or astroglial markers have also been observed in postmortem studies of mood disorders. Most of these used glial fibrillary acidic protein (GFAP) as a marker for astrocytes, and reported that GFAP, or GFAPpositive cells were decreased in mood-disordered subjects relative to controls (Johnston-Wilson et al, 2000; Si et al, 2004; Rajkowska and Miguel-Hidalgo, 2007). Because the amount of GFAP varies with the functional state of astrocytes, and GFAP staining often does not demonstrate all astrocytes, it is unclear whether these results indicate changes in astrocyte number or function. Furthermore, other studies did not find abnormalities in the number of GFAP-stained cells or GFAP levels in MDD or BD cases (Webster et al, 2001; Cotter et al, 2001b), and at least one study that used the astrocyte-specific protein S100b to identify these cells in the amygdala did not find a reduction in astrocytes in MDD cases (Hamidi et al, 2004).

Factors that may contribute to a loss of oligodendroglia include the elevated glucocorticoid secretion and glutamatergic transmission evident during depression (see below). Glucocorticoids affect both glia and neurons (Cheng and de Vellis, 2000), and elevated glucocorticoid concentrations and repeated stress decrease the proliferation of oligoden- drocyte precursors (Alonso, 2000; Banasr and Duman, 2007). Moreover, oligodendrocytes express AMPA and kainate type glutamate receptors, and are sensitive to excitotoxic damage from excess glutamate (Dewar et al, 2003; Matute et al, 1997; McDonald et al, 1998). Finally, decreases in oligodendrocyte density are probably not specific to mood disorders; in particular, in schizophrenia a reduction of oligodendrocytes has also been reported in the frontal cortex (Hof et al, 2002, 2003).

\section{Magnetic Resonance Spectroscopy (MRS) Imaging of Glutamate and GABA}

The results from MRS studies of MDD show reductions in cerebral GABA levels and in the 'Glx' peak, which reflects the combined concentrations of glutamate plus glutamine, that appear compatible with the postmortem findings of cellular reductions. Although these spectra reflect the combined intracellular and extracellular pools of glutamate-glutamine and GABA, they are dominated overwhelmingly by the intracellular pools. Depressed MDD subjects show abnormally reduced GABA levels in the dorsomedial/dorsal anterolateral PFC and occipital cortex (Sanacora et al, 1999; Hasler et al, 2007). The majority of the GABA pool exists within GABAergic neurons, so the reduction in GABA in the dorsal anterolateral PFC is compatible with the report of reduced GABAergic neurons in this region (BA9) in MDD (Rajkowska et al, 2007).

Depressed subjects also show abnormally reduced Glx levels in the dorsomedial/dorsal anterolateral and ventromedial PFC (Hasler et al, 2007). As the Glx measure reflects the intracellular glutamate and glutamine pools this abnormality appears compatible with the reductions in glial cells found postmortem in the same regions in MDD. Both perineuronal oligodendroglia and astroglia play roles in glutamate-glutamine cycling.

\section{Correlations with Rodent Models of Chronic and Repeated Stress}

In regions that appear homologous to the areas where gray matter reductions are evident in depressed humans (ie, medial PFC, hippocampus) repeated stress results in dendritic atrophy and reductions in glial cell counts in rodents (Banasr and Duman, 2007; Czeh et al, 2006; McEwen and Magarinos, 2001; Wellman, 2001; Radley et al, 2008). In the basolateral amygdala (BLA) chronic unpredictable stress also produced dendritic atrophy but chronic immobilization stress instead increased dendritic branching (Banasr and Duman, 2007; Vyas et al, 2002, 2003). Dendritic atrophy presumably would be reflected by a decrease in the volume of the neuropil, which occupies most of the gray matter volume. The similarities between the histopathological changes that accompany stressinduced dendritic atrophy in rats and those found in humans suffering from depression have led to hypotheses that homologous processes underlie the reductions in gray 
matter volume in hippocampal and PFC structures in MDD and BD (McEwen and Magarinos, 2001). In rats the stressinduced dendritic atrophy in the medial PFC was associated with impaired modulation of behavioral responses to fearconditioned stimuli (Izquierdo et al, 2006), suggesting that this process can alter emotional behavior.

The dendritic remodeling associated with repeated stress depends on interactions between the increased $N$-methyl-Daspartate (NMDA) receptor stimulation and glucocorticoid secretion (McEwen and Magarinos, 2001). Notably, the depressive subgroups (eg, BD FPDD) that show reductions in regional gray matter volume also show evidence of having elevated glutamatergic transmission and cortisol secretion (Drevets et al, 2002b). Cerebral glucose metabolism largely reflects the energetic requirements associated with glutamatergic transmission (Shulman et al, 2004). The finding that reductions in cortex volume and/or histopathological changes appear to occur specifically in regions that show hypermetabolism during depression such as the medial and orbital PFC, amygdala, ventral striatum, and cingulate cortex raises the possibility that excitatory amino acid transmission has a role in the neuropathology of mood disorders. Elevated glutamatergic transmission within discrete anatomical circuits also may explain the targeted nature of gray matter changes within mood disorders (eg, affecting left more than right sgACC) (McEwen and Magarinos, 2001; Drevets and Price, 2005a; Shansky et al, 2009).

\section{IMPLICATIONS FOR NEUROCIRCUITRY- BASED MODELS OF DEPRESSION}

The abnormalities of structure and function evident within the extended visceromotor network may impair this network's modulation of endocrine, autonomic, emotional, and behavioral responses to aversive and reward-related stimuli or contexts (Öngür et al, 2003), potentially accounting for the disturbances within these domains in mood disorders. The abnormally increased CBF and metabolism in the VLPFC, OFC, sgACC, pgACC, amygdala, ventral striatum, and medial thalamus evident in depression (Table 1; Figure 8) implicate a limbic-cortical-striato-pallido-thalamic circuit involving these structures (Drevets et al, 1992) (Figure 6). As reviewed above, the BLA, medial prefrontal network and MD are interconnected by excitatory, glutamatergic projections (Amaral and Price, 1984; Amaral and Insausti, 1992; Bacon et al, 1996; Kuroda and Price, 1991a; Jackson and Moghaddam, 2001). In agreement with the neuroimaging evidence of elevated activity in this circuit, post mortem studies of the NMDA receptor complex in suicide victims found evidence that glutamatergic transmission had been increased in the PFC antemortem in depression (Paul and Skolnick, 2003). After effective antidepressant treatment, there is evidence that metabolic activity decreases in these regions (Table 1; reviewed in Drevets et al, 2002a, 2004a), and there is desensitization of NMDA receptors in the PFC (Paul and Skolnick, 2003).
The limbic-cortical-striato-pallido-thalamic circuit constitutes a disinhibitory side loop between the amygdala or PFC and the MD. As the pallidal neurons have relatively high spontaneous firing rates (DeLong, 1972) activity in the PFC or amygdala that activates the striatum and in turn inhibits the ventral pallidum may release the MD from the inhibitory pallidal influence (Figure 6; Russchen et al, 1985; Graybiel, 1990; Kuroda and Price, 1991a,b). Notably, repeated stress results in hyperexcitability in the BLA in rodents (Shekhar et al, 2005; Vyas et al, 2006) suggesting a mechanism that might produce pathological amygdala activity in depression.

The anatomical projections from the amygdala and $\mathrm{mPFC}$ to the hypothalamus, PAG, locus ceruleus, raphe, and autonomic-related brainstem nuclei play major roles in organizing the endocrine, autonomic, and behavioral responses to stressors and emotional stimuli (Figure 10) (Davis and Shi, 1999; LeDoux, 2003; Öngür et al, 2003). In rats, stimulation of the amygdala inhibits neuronal ensemble activity in the $\mathrm{MPFC}$, and stimulation of the $\mathrm{mPFC}$ to the amygdala excites intra-amygdaloid GABAergic cells that inhibit neuronal activity in the central amygdaloid nucleus (ACe) (Likhtik et al, 2005; Perez-Jaranay and Vives, 1991). Rats exposed to fear-conditioned stimuli show reduced $\mathrm{mPFC}$ neuronal firing activity, the magnitude of which correlates inversely with the corresponding increase in amygdala neuron activity and fear behavior (Garcia et al, 1999). Conversely, lesions of the mPFC enhance behavioral, sympathetic, and endocrine responses to stressors or fearconditioned stimuli in rats (Morgan and LeDoux, 1995; Sullivan and Gratton, 1999). Such reciprocal relationships between the medial prefrontal network and amygdala may be related to the observations that in MDD depression severity correlates positively with amygdala and sgACC activity, but negatively with activity in the left VLPFC/lateral OFC (approximately BA 45a and 47s) (Drevets et al, 2004a). Thus, the increased activity seen within some medial prefrontal network areas during depressive episodes may reflect a compensatory response that modulates depressive symptoms. The neuropathological changes evident in the mPFC and amygdala in mood disorders may impair their roles in modulating visceral responses to stressors and emotional stimuli.

\section{Effects of Altered Medial Prefrontal Network- Limbic Interactions}

One neural model that could account for the neuroendocrine autonomic neurotransmitter attention and rewardseeking abnormalities associated with MDE suggests that impairment of medial prefrontal network and BLA function disinhibits the efferent transmission from the ACe and BNST to the hypothalamus and brainstem (Figure 10). The amygdala mediates the stressed component of glucocorticoid hormone secretion by disinhibiting CRF release from the hypothalamic paraventricular nucleus (Herman and Cullinan, 1997). Conversely, the glucocorticoid response to 


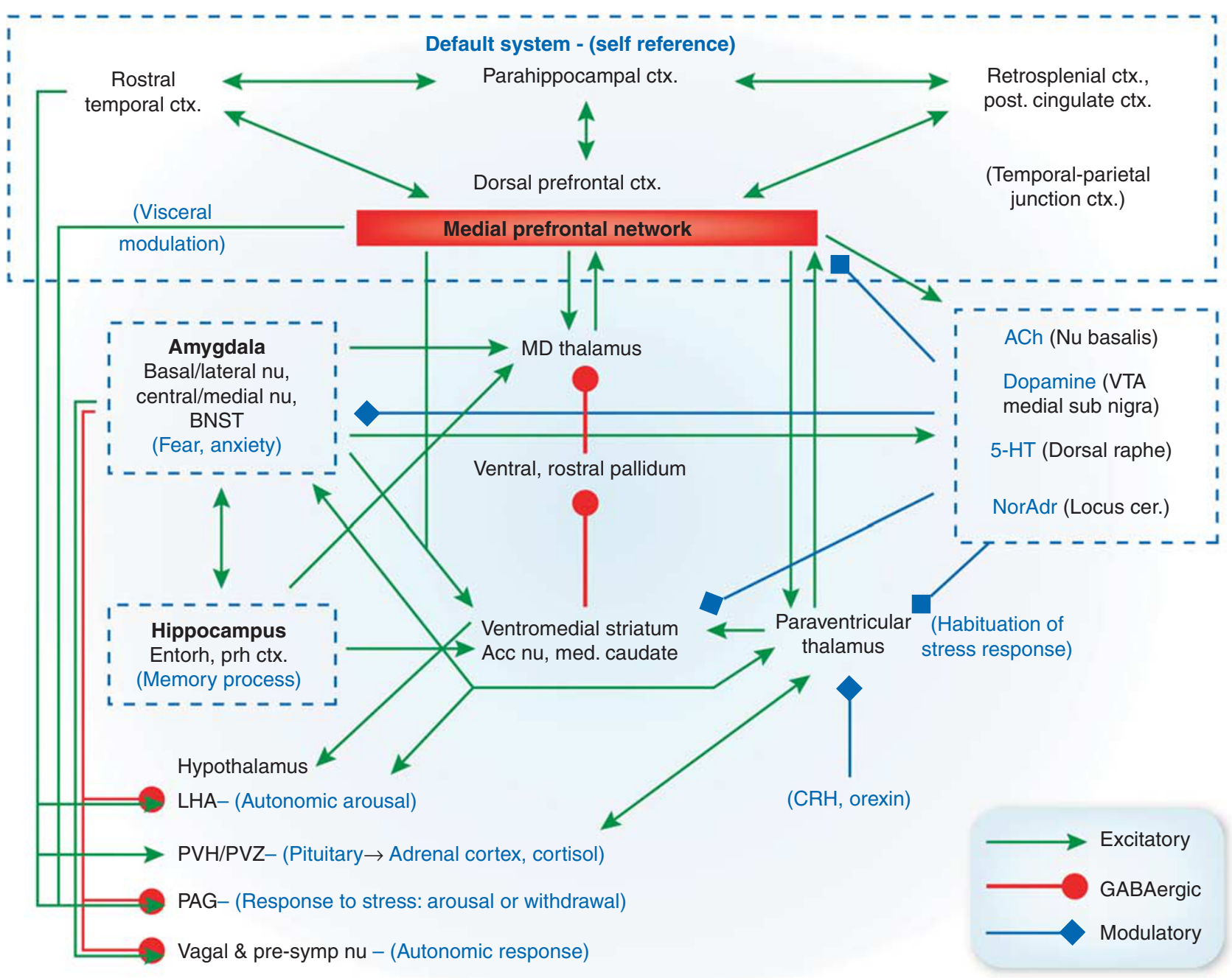

Figure 10. Anatomical circuits involving the medial prefrontal network (medial prefrontal network) and amygdala. Glutamatergic, presumed excitatory projections are shown in green, GABAergic projections are shown in orange, and modulatory projections in blue. In the model proposed here, dysfunction in the amygdala and/or the medial prefrontal network results in dysregulation of transmission throughout an extended brain circuit that stretches from the cortex to the brainstem, yielding the emotional, cognitive, endocrine, autonomic, and neurochemical manifestations of depression. Intra-amygdaloid connections link the basal and lateral amygdaloid nuclei to the central and medial nuclei of the amygdala and the bed nucleus of the stria terminalis (BNST). Parallel and convergent efferent projections from the amygdala and the medial prefrontal network to the hypothalamus, periaqueductal gray (PAG), nucleus basalis, locus ceruleus, dorsal raphe, and medullary vagal nuclei organize neuroendocrine, autonomic, neurotransmitter and behavioral responses to stressors and emotional stimuli (Davis and Shi, 1999, LeDoux, 2003). In addition, the amygdala and medial prefrontal network interact with the same cortico-striatal-pallidal-thalamic loop, through prominent connections both with the accumbens nucleus and medial caudate, and with the mediodorsal and paraventricular thalamic nuclei, which may function to control and limit responses to stress. Finally, the medial prefrontal network is a central node in the cortical 'default system' that appears to support self-referential functions such as mood. Other abbreviations: 5-HT_serotonin; ACh—acetylcholine; Cort. — corticosteroid; $\mathrm{CRH}$-corticotrophin releasing hormone; Ctx-cortex; NorAdrnorepinephrine; PVN - paraventricular nucleus of the hypothalamus; PVZ_-periventricular zone of hypothalamus; STGr - rostral superior temporal gyrus - VTA — ventral tegmental area.

stress is inhibited by stimulation of glucocorticoid receptors in the ventral ACC, such that lesions in this cortex in rats increase ACTH and CORT secretion during stress (Diorio et al, 1993). Severe depression is associated with hypersecretion of cortisol during the circadian nadir, pituitary and adrenal gland enlargement, and CSF-CRF levels that are increased to an extent that is inappropriate to the plasma cortisol concentrations, and both deficits in negative feedback systems and excessive central stimulation of the secretion of CRF and/or other ACTH secretagogues are implicated in mood disorders (Gold and Chrousos, 2002;
Drevets et al, 2004a; Swaab et al, 2005; Carroll et al, 2007). Depressed subjects also show exaggerated cortisol responses to stress (Drevets et al, 1999, 2002b) suggesting the hypothesis that excessive amygdala activity combined with reduced ventral ACC gray matter contributes to the abnormal HPA-axis response to stress in depression (Drevets et al, 2002b; McEwen and Magarinos, 2001; Gold et al, 2002).

The autonomic imbalance associated with depression also could reflect medial network dysfunction coupled with excessive amygdala activity. Patients with MDD show an 
excessive risk of cardiac events, such as ventricular arrhythmia and sudden death, which are hypothesized to result partly from elevated noradrenergic and sympathetic autonomic function coupled with reduced parasympathetic tone on the heart rate (Carney et al, 2005). Stimulation of the projections from the $\mathrm{ACe}$ and BNST in rats increases sympathetic autonomic arousal in rodents, presumably via projections to the lateral hypothalamus, PAG, locus ceruleus, and ponto-medullary reticular formation (LeDoux, 2003; Gold and Chrousos, 2002). Similarly, lesions in rats of the infralimbic cortex (posterior sgACC) reduce the heart rate response to a conditioned emotional stimulus, apparently because of a reduction in the sympathetic tachycardia response (Frysztak and Neafsey, 1994). In rats there is a direct projection from the sgACC to the autonomic nuclei in the medulla (Terreberry and Neafsey, 1987); although this has not been found in primates (An et al, 1998; Freedman et al, 2000), it may be expected that multisynaptic pathways would serve a similar function. It may be hypothesized that the effects of increased amygdala activity and reduced infralimbic cortex function accounts for the autonomic imbalance seen in depression (Drevets et al, 1998).

Dysfunction of the medial prefrontal network also may contribute to the anhedonia, lack of motivation, and inattention manifest in depression. The ACC receives extensive dopaminergic innervation from the VTA and sends projections to the VTA that regulate phasic dopamine (DA) release. In rats, stimulation of these ventral ACC areas elicits burst-firing patterns in the VTA-DA neurons whereas inactivation of the ventral ACC converts burstfiring patterns to pacemaker-like firing activity (Drevets et al, 1998; Murase et al, 1993; Taber and Fibiger, 1993; Gariano and Groves, 1988). The burst-firing patterns increase DA release in the accumbens, which may encode information about reward prediction in monkeys (Schultz et al, 1997). The mesolimbic DA projections from the VTA to the nucleus accumbens shell and the mPFC thus have major roles in learning associations between operant behaviors, or sensory stimuli and reward, and in mediating the reinforcing properties of natural rewards such as food and sex (Nestler and Carlezon, 2006).

Martin-Soelch et al (2008) found that depressed subjects showed less DA release than healthy controls in response to unpredicted monetary reward. Reduction in mesolimbic dopaminergic function previously had been hypothesized to underlie the anhedonia and amotivation associated with depression, based upon evidence that DA depletion caused by degeneration of DA neurons (in Parkinson's Disease) or drugs (reserpine $\alpha$-methyl-para-tyrosine) induced depressive syndromes in vulnerable individuals (Santamaria et al, 1986; Hasler et al, 2008). In addition, depressed subjects showed abnormal reductions in the CSF and jugular vein plasma levels of the DA metabolite homovanillic acid (Willner, 1995; Lambert et al, 2000), striatal DA transporter binding (Meyer et al, 2001), [ $\left.{ }^{11} \mathrm{C}\right] \mathrm{L}-\mathrm{DOPA}$ uptake across the blood-brain barrier (Ågren et al, 1993), and striatal dopamine $D_{1}$ receptor binding (Cannon et al, 2009). If the neuropathological changes extant within the ACC in mood disorders interfere with the cortical drive on VTA-DA neuronal burst-firing activity, they may impair perception or learning of reward, and potentially interfere with behavioral engagement in pleasurable or positively reinforcing activities.

Finally, the cognitive and behavioral response patterns supporting goal- or reward-directed activity are thought to depend upon PFC inputs to the ventral striatum, which are maintained or 'gated' by projections from the hippocampus (subiculum) to the ventral striatum (Goto and Grace, 2005). Stimulation of projections from the amygdala to the ventral striatum interrupts the maintenance of these cortically driven response patterns, providing an adaptive over-ride that interrupts goal-directed thought or behavior in response to threat or novelty. Pathologically elevated amygdala activity during MDE could interfere with cognitive performance and goal-directed behavior to an extent that is maladaptive.

\section{Antidepressant Treatment Effects}

Mood disorders have been associated with abnormalities of serotonergic, dopaminergic, noradrenergic, cholinergic, glutamatergic, GABAergic, glucocorticoid, and peptidergic function (Drevets et al, 2007; Nestler and Carlezon, 2006; Krystal et al, 2002; Gold et al, 2002). Antidepressant drugs (AD) impact these systems through either primary or secondary pharmacological actions. Moreover, the delayed onset of AD's clinical effects suggests that secondary mechanisms involving changes in gene expression and/or synaptic plasticity may contribute to their therapeutic mechanisms. Some of the final common pathways that have been hypothesized to underlie antidepressant responses include: (1) increases in the gene expression of brain-derived neurotrophic factor (BDNF) and other neurotrophic or neuroprotective factors (Manji et al, 2001; Santarelli et al, 2003); (2) enhancement of postsynaptic serotonin type $1 \mathrm{~A}\left(5-\mathrm{HT}_{1 \mathrm{~A}}\right)$ receptor function (Haddjeri et al, 1998; Chaput et al, 1991); (3) attenuation of the sensitivity or transmission of NMDA-glutamatergic receptors and enhancement of GABA transmission (Krystal et al, 2002; Paul and Skolnick, 2003).

Considering the effects of diverse antidepressant treatments on circuitry-based models may elucidate common neurophysiological mechanisms that underlie therapeutic benefits. For example, neurophysiological activity in the amygdala decreases in rats, monkeys, and/or humans during several antidepressant treatments, including drugs, vagal nerve stimulation, or deep brain stimulation of the anterior capsule, potentially reducing efferent transmission via the ACe (Drevets et al, 2002a; Sheline et al, 2001; Fu et al, 2004; Van Laere et al, 2006; Gerber et al, 1983; Henry et al, 1998). Notably, in rats Horovitz (1966) observed that injection of antidepressant drugs into the amygdala 
produced identical effects as lesions of the ACe in animal models used to predict antidepressant drug efficacy.

In addition, data support the importance of modulating activity within the limbic-cortical-striato-pallido-thalamic circuitry in the treatment of depression. Functional imaging studies in depressed humans indicate that metabolism and blood flow decrease in the sgACC/ ventromedial PFC in response to chronic treatment with antidepressant drugs, vagus nerve stimulation, or deep brain stimulation of the sgACC or anterior capsule (Mayberg et al, 1999, 2005; Drevets et al, 2002a; Van Laere et al, 2006; Nahas et al, 2007; Conway et al, 2006). Activity in the broader limbic-thalamo-cortical circuitry also decreases during effective treatment with antidepressant drugs or electroconvulsive therapy (Drevets et al, 2002a, 2004a). Preliminary reports indicate that chronic SSRI treatment or deep brain stimulation of the anterior capsule also reduces the abnormally elevated metabolism in the accumbens area in depression (Drevets et al, 2006) or in depression associated with obsessive-compulsive disorder (Van Laere et al, 2006), deep brain stimulation applied via electrodes situated in the accumbens area/ventral internal capsule improves depressive symptoms in treatmentrefractory depression (Malone et al, 2009; Schlaepfer et al, 2008).

Cognitive-behavioral strategies for managing depressive symptoms may more specifically rely upon enhancing the function of OMPFC systems that modulate limbic activity thereby enhancing the normal role of cortico-limbic circuits in modulating emotional expression and experience (Siegle et al, 2006). For example interpersonal psychotherapy can reduce depressive symptoms in MDD, and has been shown to enhance activity in the intrasulcal portion of BA 47 (Brody et al, 2001), based on comparison of the stereotaxic coordinates for the anterior insula region reported in this paper with the cytoarchitectonic maps from Öngür et al (2003).

\section{FUTURE DIRECTIONS}

Convergent results from studies conducted using neuroimaging lesion analysis, and postmortem techniques support models in which the signs and symptoms of depression emanate from dysfunction within an extended visceromotor network that interferes with this system's modulation of emotional behavior (Figure 10). We propose more specifically that impaired function within the circuits formed by the medial prefrontal network and anatomically related limbic structures can account for the disturbances of emotional processing, cognitive performance, neurotransmission, autonomic regulation, and neuroendocrine responses associated with mood disorders. Antidepressant therapies may compensate for this dysfunction by modulating the pathological limbic activity that putatively mediates depressive symptoms (Drevets et al, 2002a), or by enhancing the expression of neurotrophic factors that protect medial network function from the effects of repeated stress (Manji et al, 2001).

In further development of the neuroanatomical circuits discussed here, two directions can be mentioned. First, it is important to better define in monkeys the wider cortical system related to the medial prefrontal system, particularly in the dorsal prefrontal cortex, and in the posterior cingulate cortex. Experiments are currently being analyzed that will contribute to this process, but the work to date has only outlined the system as a whole. Much more investigation will be required to determine the differential functions of the structures and areas within the system, and how they work together.

Second, it is critical to better translate the experimental results in monkeys to humans. The human brain is not just an enlarged monkey brain, and it is often difficult to know how to correlate the two; the cerebral cortex is especially difficult because of the large size of the human cortex, and the subtle nature of most architectonic markers between cortical areas. Although Brodmann (1909) provided remarkable architectonic maps of the cortex of humans and several animal species, his maps are no longer able to encompass the large amount of data that has been obtained in the 100 years since the publication of his major work. It is very important that new architectonic analysis of the human cortex be done, with the express intention of correlation with data from experimental animals. This is particularly significant because of the new imaging methods such as 'functional connectivity,' MRI, and diffusion tensor imaging that can provide information about cortical circuits in humans; to interpret data gathered with these methods it is important to have a detailed and nuanced map of the cortical mosaic that reflects current understanding of cortical organization and function.

From a clinical viewpoint, elucidation of the functional relationships between various components of the neurocircuits underlying emotional processing is needed to establish a nosology for mood disorders that is based upon pathophysiology. Researchers have long awaited such a paradigm shift because the nosology based on clinical syndromes, which is embodied in conventional DSM-IV criteria, has proven insufficient to guide the design of studies that can discover disease mechanisms. A circuitbased approach is also needed to better characterize specific types of dysregulation in emotion processing, in order to update the phenomenology of mood disorders. This process may illuminate the neurobiological bases for both the differences and the commonality seen between mood and anxiety disorders, as well as for syndromes such as social phobia, panic disorder, post-traumatic stress disorder, and eating disorders that commonly occur co-morbidly with depression. Finally, neurocircuitry-based approaches may facilitate advances in interventional therapies such as deep brain stimulation, by pinpointing nodes that could provide effective treatments for depression, and identifying the patients who are likely to benefit from such interventions. 


\section{ACKNOWLEDGEMENTS}

JLP was supported by Grant R01 MH070941 from the USPHS/NIMH.

\section{DISCLOSURE}

We declare that except for income received from our primary employers, no financial support or compensation has been received from any individual or corporate entity over the past 3 years for research or professional service, and there are no personal financial holdings that could be perceived as constituting a potential conflict of interest.

\section{REFERENCES}

Adler CM, Delbello MP, Jarvis K, Levine A, Adams J, Strakowski SM (2007). Voxel-based study of structural changes in first-episode patients with bipolar disorder. Biol Psychiatry 61: 776-781.

Ågren HRL, Hartvig P, Tedroff J, Bjurling P, Lundqvist H, Långström B (1993). Monoamine metabolism in human prefrontal cortex and basal ganglia. PET studies using [11C]L-hydroxytryptophan and [11C]L-DOPA in healthy volunteers and patients with unipolar depression. Depression 1: 71-81.

Alonso G (2000). Prolonged corticosterone treatment of adult rats inhibits the proliferation of oligodendrocyte progenitors present throughout white and gray matter regions of the brain. Glia 31: 219-231.

Amaral DG, Insausti R (1992). Retrograde transport of D-[3H]-aspartate injected into the monkey amygdaloid complex. Exp Brain Res 88: 375-388.

Amaral DG, Price JL (1984). Amygdalo-cortical projections in the monkey (Macaca fascicularis). J Comp Neurol 230: 465-496.

Amaral DG, Price JL, Pitkanen A, Carmichael ST (1992). Anatomical organization of the primate amygdaloid complex. In: Aggleton J (ed). The Amygdala: Neurobiological Aspects of Emotion Memory and Mental Dysfunction. WileyLiss: New York. pp 1-66.

An X, Bandler R, Ongur D, Price JL (1998). Prefrontal cortical projections to longitudinal columns in the midbrain periaqueductal gray in macaque monkeys. J Comp Neurol 401: 455-479.

APA (1994). Diagnostic and Statistical Manual of Mental Disorders (DSM-IV). APA Press: Washington DC.

Arbelaez AM, Powers WJ, Videen TO, Price JL, Cryer PE (2008). Attenuation of counterregulatory responses to recurrent hypoglycemia by active thalamic inhibition: a mechanism for hypoglycemia-associated autonomic failure. Diabetes 57: 470-475.

Aston C, Jiang L, Sokolov BP (2005). Transcriptional profiling reveals evidence for signaling and oligodendroglial abnormalities in the temporal cortex from patients with major depressive disorder. Mol Psychiatry 10: 309-322.

Bacon SJ, Headlam AJ, Gabbott PL, Smith AD (1996). Amygdala input to medial prefrontal cortex (mPFC) in the rat: a light and electron microscope study. Brain Res 720: 211-219.

Banasr M, Duman RS (2007). Regulation of neurogenesis and gliogenesis by stress and antidepressant treatment. CNS Neurol Disord Drug Targets 6: 311-320.

Barbas H, De Olmos J (1990). Projections from the amygdala to basoventral and mediodorsal prefrontal regions in the rhesus monkey. J Comp Neuro/ 300: 549-571.

Barbas H, Saha S, Rempel-Clower N, Ghashghaei T (2003). Serial pathways from primate prefrontal cortex to autonomic areas may influence emotional expression. BMC Neurosci 4: 25.

Bard $P$ (1928). A diencephalic mechanism for the expression of rage with special reference to the sympathetic nervous system. Am J Physiol 84: 490-513.

Bauer M, London ED, Rasgon N, Berman SM, Frye MA, Altshuler LL et al (2005). Supraphysiological doses of levothyroxine alter regional cerebral metabolism and improve mood in bipolar depression. Mol Psychiatry 10: 456-469.

Baumann BDP, Krell D, Diekmann S, Leschinger A, Stauch R, Wurthman C et al (1999). Reduced volume of limbic system-affiliated basal ganglia in mood disorders: preliminary data from a post mortem study. J Neuropsych Clin Neurosci 11: 71-78.

Bechara A, Damasio H, Damasio AR (2000). Emotion, decision making and the orbitofrontal cortex. Cereb Cortex 10: 295-307.

Benes FM, Vincent SL, Todtenkopf M (2001). The density of pyramidal and nonpyramidal neurons in anterior cingulate cortex of schizophrenic and bipolar subjects. Biol Psychiatry 50: 395-406.
Bhatnagar S, Huber R, Nowak N, Trotter P (2002). Lesions of the posterior paraventricular thalamus block habituation of hypothalamic-pituitary-adrenal responses to repeated restraint. J Neuroendocrinol 14: 403-410.

Boes AD, McCormick LM, Coryell WH, Nopoulos P (2008). Rostral anterior cingulate cortex volume correlates with depressed mood in normal healthy children. Biol Psychiatry 63: 391-397.

Botteron KN, Raichle ME, Drevets WC, Heath AC, Todd RD (2002). Volumetric reduction in left subgenual prefrontal cortex in early-onset depression. Biol Psychiatry 51: 342-344.

Bowen DM, Nailerahim A, Procter AW, Francis PT, Murphy E (1989). Circumscribed changes of the cerebral cortex in neuropsychiatric disorders of later life. Proc Natl Acad Sci USA 86: 9504-9508.

Bowley MP, Drevets WC, Öngür D, Price JL (2002). Low glial numbers in the amygdala in major depressive disorder. Biol Psychiatry 52: 404-412.

Bradley BP, Mogg K, Williams R (1995). Implicit and explicit memory for emotioncongruent information in clinical depression and anxiety. Behav Res Ther 33: $755-720$

Brambilla P, Nicoletti M, Sassi RB, Mallinger AG, Frank E, Keshavan MS et al (2004). Corpus callosum signal intensity in patients with bipolar and unipolar disorder. J Neurol Neurosurg Psychiatry 75: 221-225.

Broca P (1878). Anatomie comparee des circonvolutions cerebrales. Le grand lobe limbique et la scissure lilmbique dans la serie des mammiferes. Rev Anthropol I Ser 2: 385-498.

Brody AL, Saxena S, Stoessel P, Gillies LA, Fairbanks LA, Alborzian S et al (2001). Regional brain metabolic changes in patients with major depression treated with either paroxetine or interpersonal therapy: preliminary findings. Arch Gen Psychiatry 58: 631-640.

Brodmann K (1909). Vergleichende Lokalisationslehre der Grosshirnrinde in irhen Prinzipien dargestellt auf Grund des Zellenbaues. JA Barth, Leipzig.

Broomfield NM, Davies R, Macmahon K, Ali F, Cross SM (2007). Further evidence of attention bias for negative information in late life depression. Int $J$ Geriatr Psychiatry 22: 175-180.

Bubser M, Deutch AY (1999). Stress induces fos expression in neurons of the thalamic paraventricular nucleus that innervate limbic forebrain sites. Synapse 32: 13-22.

Buckwalter JA, Schumann CM, Van Hoesen GW (2008). Evidence for direct projections from the basal nucleus of the amygdala to retrosplenial cortex in the Macaque monkey. Exp Brain Res 186: 47-57.

Bush G, Luu P, Posner Ml (2000). Cognitive and emotional influences in anterior cingulate cortex. Trends Cogn Sci 4: 215-222.

Calzavara R, Mailly P, Haber SN (2007). Relationship between the corticostriatal terminals from areas 9 and 46 and those from area $8 \mathrm{~A}$ dorsal and rostral premotor cortex and area 24c: an anatomical substrate for cognition to action. Eur J Neurosci 26: 2005-2024.

Cannon DM, Klaver JM, Peck SA, Rallis-Voak D, Erickson K, Drevets WC (2009). Dopamine type-1 receptor binding in major depressive disorder assessed using positron emission tomography and [11C]NNC-112. Neuropsychopharmacology 34: 1277-1287.

Carmichael ST, Clugnet M-F, Price JL (1994). Central olfactory connections in the macaque monkey. J Comp Neurol 346: 403-434.

Carmichael ST, Price JL (1994). Architectonic subdivision of the orbital and medial prefrontal cortex in the macaque monkey. J Comp Neurol 346: 366-402.

Carmichael ST, Price JL (1995a). Limbic connections of the orbital and medial prefrontal cortex in macaque monkeys. J Comp Neurol 363: 615-641.

Carmichael ST, Price JL (1995b). Sensory and premotor connections of the orbital and medial prefrontal cortex. J Comp Neurol 363: 642-664.

Carmichael ST, Price JL (1996). Connectional networks within the orbital and medial prefrontal cortex of macaque monkeys. J Comp Neurol 371: 179-207.

Carney RM, Freedland KE, Veith RC (2005). Depression the autonomic nervous system and coronary heart disease. Psychosom Med 67: S29-S33.

Carroll BJ, Cassidy F, Naftolowitz D, Tatham NE, Wilson WH, Iranmanesh A et al (2007). Pathophysiology of hypercortisolism in depression. Acta Psychiatr Scand Supp/ 433: 90-103.

Caspi A, Sugden K, Moffitt TE, Taylor A, Craig IW, Harrington H et al (2003). Influence of life stress on depression: moderation by a polymorphism in the 5-HTT gene. Science 301: 386-389.

Chaput Y, de Montigny C, Blier P (1991). Presynaptic and postsynaptic modifications of the serotonin system by long-term administration of antidepressant treatments. An in vivo electrophysiologic study in the rat. Neuropsychopharmacology 5: 219-229.

Cheng JD, de Vellis J (2000). Oligodendrocytes as glucocorticoids target cells: functional analysis of the glycerol phosphate dehydrogenase gene. J Neurosci Res 59: 436-445.

Churchill L, Zahm DS, Kalivas PW (1996). The mediodorsal nucleus of the thalamus in rats-I. Forebrain gabaergic innervation. Neuroscience 70: 93-102. 
Clark CP, Brown GG, Frank L, Thomas L, Sutherland AN, Gillin JC (2006). Improved anatomic delineation of the antidepressant response to partial sleep deprivation in medial frontal cortex using perfusion-weighted functional MRI. Psychiatry Res 146: 213-222.

Conway CR, Sheline Y, Chibnall JT, George MS, Fletcher JW, Mintun MA (2006). Cerebral blood flow changes during vagus nerve stimulation for depression. Psychiatry Res 146: 179-184.

Corbetta M, Kincade JM, Shulman GL (2002). Neural systems for visual orienting and their relationships to spatial working memory. J Cogn Neurosci 14: 508-523.

Coryell W, Nopoulos P, Drevets W, Wilson T, Andreasen NC (2005). Subgenual prefrontal cortex volumes in major depressive disorder and schizophrenia: diagnostic specificity and prognostic implications. Am J Psychiatry 162: 1706-1712.

Cotter D, Mackay D, Chana G, Beasley C, Landau S, Everall IP (2002). Reduced neuronal size and glial cell density in area 9 of the dorsolateral prefrontal cortex in subjects with major depressive disorder. Cereb Cortex 12: 386-394.

Cotter D, Mackay D, Landau S, Kerwin R, Everall I (2001a). Reduced glial cell density and neuronal size in the anterior cingulate cortex in major depressive disorder. Arch Gen Psychiatry 58: 545-553.

Cotter DR, Pariante CM, Everall IP (2001b). Glial cell abnormalities in major psychiatric disorders: the evidence and implications. Brain Res Bull 55: 585-595.

Cowan WM, Raisman G, Powell TP (1965). The Connexions of the Amygdala. J Neurol Neurosurg Psychiatry 28: 137-151.

Critchley HD, Elliott R, Mathias CJ, Dolan RJ (2000). Neural activity relating to generation and representation of galvanic skin conductance responses: a functional magnetic resonance imaging study. J Neurosci 20: 3033-3040.

Critchley HD, Mathias CJ, Josephs O, O'Doherty J, Zanini S, Dewar BK et al (2003). Human cingulate cortex and autonomic control: converging neuroimaging and clinical evidence. Brain 126: 2139-2152.

Cryer PE (2004). Diverse causes of hypoglycemia-associated autonomic failure in diabetes. N Engl J Med 350: 2272-2279.

Czeh B, Simon M, Schmelting B, Hiemke C, Fuchs E (2006). Astroglial plasticity in the hippocampus is affected by chronic psychosocial stress and concomitant fluoxetine treatment. Neuropsychopharmacology 31: 1616-1626.

D'Amelio F, Eng LF, Gibbs MA (1990). Glutamine synthetase immunoreactivity is present in oligodendroglia of various regions of the central nervous system. Glia 3: 335-341.

Damasio AR (1994). Descartes' error and the future of human life. Sci Am 271: 144.

Damasio AR, Tranel D, Damasio H (1990). Individuals with sociopathic behavior caused by frontal damage fail to respond autonomically to social stimuli. Behav Brain Res 41: 81-94.

Davis M, Shi C (1999). The extended amygdala: are the central nucleus of the amygdala and the bed nucleus of the stria terminalis differentially involved in fear versus anxiety? Ann N Y Acad Sci 877: 281-291.

Delong MR (1972). Activity of basal ganglia neurons during movement. Brain Res 40: $127-135$

Dewar D, Underhill SM, Goldberg MP (2003). Oligodendrocytes and ischemic brain injury. J Cereb Blood Flow Metab 23: 263-274.

Diorio D, Viau V, Meaney MJ (1993). The role of the medial prefrontal cortex (cingulate gyrus) in the regulation of hypothalamic-pituitary-adrenal responses to stress. J Neurosci 13: 3839-3847.

Drevets WC (2001). Neuroimaging and neuropathological studies of depression: implications for the cognitive-emotional features of mood disorders. Curr Opin Neurobiol 11: 240-249.

Drevets WC (2007). Orbitofrontal cortex function and structure in depression. Ann NY Acad Sci 1121: 499-527.

Drevets WC, Bogers W, Raichle ME (2002a). Functional anatomical correlates of antidepressant drug treatment assessed using PET measures of regional glucose metabolism. Eur Neuropsychopharmacol 12: 527-544.

Drevets WC, Frank E, Price JC, Kupfer DJ, Holt D, Greer PJ et al (1999). PET imaging of serotonin $1 \mathrm{~A}$ receptor binding in depression. Biol Psychiatry 46: 1375-1387.

Drevets WC, Gadde K, Krishnan KRR (2004a). Neuroimaging studies of mood disorder. In: Charney DS, Nestler EJ (eds). Neurobiology of Mental IIIness, 2nd edn. Oxford University Press: New York. pp 461-480.

Drevets WC, Gautier C, Lowry T, Bogers W, Greer P, Kupfer DJ (2001). Abnormal hemodynamic responses to facially expressed emotion in major depression. Soc Neurosci Abstr 27: 785.1.

Drevets WC, Kupfer DJ, Bogers W, Thase M (2006). Glucose metabolism in dorsal versus ventral striatum differentiates major depressive subtypes. Program No. 782.8. Neuroscience Meeting Planner. Atlanta, GA: Society for Neuroscience, 2006, Online.

Drevets WC, Öngür D, Price JL (1998). Neuroimaging abnormalities in the subgenual prefrontal cortex: implications for the pathophysiology of familial mood disorders. Mol Psychiatry 3: 220-226.
Drevets WC, Price JL (2005). Neuroimaging and neuropathological studies of mood disorders. In: Licinio JWM (ed). Biology of Depression: From Novel Insights to Therapeutic Strategies. Wiley-VCH Verlag GmbH \& Co.: Weinheim Germany. pp 427-466.

Drevets WC, Price JL, Bardgett ME, Reich T, Todd RD, Raichle ME (2002b). Glucose metabolism in the amygdala in depression: relationship to diagnostic subtype and plasma cortisol levels. Pharmacol Biochem Behav 71: 431-447.

Drevets WC, Price JL, Simpson Jr JR, Todd RD, Reich T, Vannier M et al (1997). Subgenual prefrontal cortex abnormalities in mood disorders. Nature 386 824-827.

Drevets WC, Raichle ME (1998). Reciprocal suppression of regional cerebral blood flow during emotional versus higher cognitive processes: implications for interactions between emotion and cognition. Cogn Emot 12: 353-385.

Drevets WC, Ryan N, Bogers W, Birmaher B, Axelson D, Dahl R (2004b). Subgenual prefrontal cortex volume decreased in healthy humans at high familia risk for mood disorders. Soc Neurosci Abs 799: 18.

Drevets WC, Savitz J, Trimble M (2008). The subgenual anterior cingulate cortex in mood disorders. CNS Spectr 13: 663-681.

Drevets WC, Thase ME, Moses-Kolko EL, Price J, Frank E, Kupfer DJ et al (2007). Serotonin-1A receptor imaging in recurrent depression: replication and literature review. Nucl Med Biol 34: 865-877.

Drevets WC, Todd RD (2005). Depression mania and related disorders. In: Rubin E, Zorumski C (eds). Adult Psychiatry, 2nd edn. Blackwell Publishing Ltd: Oxford. pp 91-129.

Drevets WC, Videen TO, Price JL, Preskorn SH, Carmichael ST, Raichle ME (1992). A functional anatomical study of unipolar depression. J Neurosci 12: 3628-3641.

Dunn RT, Kimbrell TA, Ketter TA, Frye MA, Willis MW, Luckenbaugh DA et al (2002). Principal components of the Beck Depression Inventory and regional cerebral metabolism in unipolar and bipolar depression. Biol Psychiatry 51: 387-399.

Eastwood SL, Harrison PJ (2000). Hippocampal synaptic pathology in schizophrenia bipolar disorder and major depression: a study of complexin mRNAs. Mol Psychiatry 5: 425-432.

Eastwood SL, Harrison PJ (2001). Synaptic pathology in the anterior cingulate cortex in schizophrenia and mood disorders. A review and a Western blot study of synaptophysin GAP-43 and the complexins. Brain Res Bull 55: 569-578.

Elliott R, Rubinsztein JS, Sahakian BJ, Dolan RJ (2000). Selective attention to emotional stimuli in a verbal go/no-go task: an fMRI study. Neuroreport 11: 1739-1744.

Erickson K, Drevets WC, Clark L, Cannon DM, Bain EE, Zarate Jr CA et al (2005). Mood-congruent bias in affective go/no-go performance of unmedicated patients with major depressive disorder. Am J Psychiatry 162: 2171-2173.

Ferry AT, Lu X-CM, Price JL (2000a). Effects of excitotoxic lesions in the ventral striatopallidal-thalamic pathway on odor reversal learning to extinguish an incorrect response. Exp Brain Res 131: 320-335.

Ferry AT, Öngür D, An X. Price JL (2000b). Prefrontal cortical projections to the striatum in macaque monkeys: evidence for an organization related to prefrontal networks. J Comp Neurol 425: 447-470.

Folstein MF, Robinson R, Folstein S, McHugh PR (1985). Depression and neurological disorders. New treatment opportunities for elderly depressed patients. J Affect Disord Supp/ 1: S11-S14.

Freedman LJ, Insel TR, Smith Y (2000). Subcortical projections of area 25 (subgenual cortex) of the macaque monkey. J Comp Neurol 421: 172-188.

Frysztak RJ, Neafsey EJ (1994). The effect of medial frontal cortex lesions on cardiovascular conditioned emotional responses in the rat. Brain Res 643: 181-193.

Fu CH, Williams SC, Cleare AJ, Brammer MJ, Walsh ND, Kim J et al (2004). Attenuation of the neural response to sad faces in major depression by antidepressant treatment: a prospective event-related functional magnetic resonance imaging study. Arch Gen Psychiatry 61: 877-889.

Gallardo-Perez M, Banos-Rivera RM, Belloch-Fuster A, Ruiperez-Rodriguez MA (1999). Attentional biases and vulnerability to depression. Span J Psycho/ 2: 11-19.

Garcia R, Vouimba RM, Baudry M, Thompson RF (1999). The amygdala modulates prefrontal cortex activity relative to conditioned fear. Nature 402: 294-296.

Gariano RF, Groves PM (1988). Burst firing induced in midbrain dopamine neurons by stimulation of the medial prefrontal and anterior cingulate cortices. Brain Res 462: 194-198.

George MS, Ketter TA, Parekh PI, Horwitz B, Herscovitch P, Post RM (1995). Brain activity during transient sadness and happiness in healthy women. Am J Psychiatry 152: 341-351.

Gerber JD, Choki CJ, Brunswick DJ, Reivich M, Frazer A (1983). The effect of antidepressant drugs on regional cerebral glucose utilization in the rat. Brain Res 269: 319-325. 
Gillath O, Bunge SA, Shaver PR, Wendelken C, Mikulincer M (2005). Attachmentstyle differences in the ability to suppress negative thoughts: exploring the neural correlates. Neuroimage 28: 835-847.

Gold PW, Chrousos GP (2002). Organization of the stress system and its dysregulation in melancholic and atypical depression: high vs low $\mathrm{CRH} / \mathrm{NE}$ states. Mol Psychiatry 7: 254-275.

Gold PW, Drevets WC, Charney DS (2002). New insights into the role of cortisol and the glucocorticoid receptor in severe depression. Biol Psychiatry 52: 381-385.

Gotlib IH, Kasch KL, Traill S, Joormann J, Arnow BA, Johnson SL (2004a). Coherence and specificity of information-processing biases in depression and social phobia. J Abnorm Psychol 113: 386-398.

Gotlib $॥$, Krasnoperova E, Yue DN, Joormann J (2004b). Attentional biases for negative interpersonal stimuli in clinical depression. J Abnorm Psychol 113: 121-135.

Goto Y, Grace AA (2005). Dopaminergic modulation of limbic and cortical drive of nucleus accumbens in goal-directed behavior. Nat Neurosci 8: 805-812.

Graybiel AM (1990). Neurotransmitters and neuromodulators in the basal ganglia. Trends Neurosci 13: 244-254.

Grimm S, Boesiger P, Beck J, Schuepbach D, Bermpohl F, Walter M et al (2009). Altered negative BOLD responses in the default-mode network during emotion processing in depressed subjects. Neuropsychopharmacology 34: 932-843.

Gusnard DA, Akbudak E, Shulman GL, Raichle ME (2001). Medial prefrontal cortex and self-referential mental activity: relation to a default mode of brain function. Proc Natl Acad Sci USA 98: 4259-4264.

Haber SN, Kunishio K, Mizobuchi M, Lynd-Balta E (1995). The orbital and medial prefrontal circuit through the primate basal ganglia. J Neurosci 15: 4851-4867.

Haddjeri N, Blier P, de Montigny C (1998). Long-term antidepressant treatments result in a tonic activation of forebrain 5-HT1A receptors. J Neurosci 18: 10150-10156.

Hamidi M, Drevets WC, PRICE JL (2004). Glial reduction in amygdala in major depressive disorder is due to oligodendrocytes. Biol Psychiatry 55: 563-569.

Hasler G, Fromm S, Carlson PJ, Luckenbaugh DA, Waldeck T, Geraci M et al (2008). Neural response to catecholamine depletion in unmedicated subjects with major depressive disorder in remission and healthy subjects. Arch Gen Psychiatry 65: 521-531.

Hasler G, Van Der Veen JW, Tumonis T, Meyers N, Shen J, Drevets WC (2007). Reduced prefrontal glutamate/glutamine and gamma-aminobutyric acid levels in major depression determined using proton magnetic resonance spectroscopy. Arch Gen Psychiatry 64: 193-200.

Hastings RS, Parsey RV, Oquendo MA, Arango V, Mann JJ (2004). Volumetric analysis of the prefrontal cortex amygdala and hippocampus in major depression. Neuropsychopharmacology 29: 952-959.

Haznedar MM, Roversi F, Pallanti S, Baldini-Rossi N, Schnur DB, Licalzi EM et al (2005). Fronto-thalamo-striatal gray and white matter volumes and anisotropy of their connections in bipolar spectrum illnesses. Biol Psychiatry 57: 733-742.

Henry TR, Bakay RA, Votaw JR, Pennell PB, Epstein CM, Faber TL et al (1998). Brain blood flow alterations induced by therapeutic vagus nerve stimulation in partial epilepsy: I. Acute effects at high and low levels of stimulation. Epilepsia 39: 983-990.

Herman JP, Cullinan WE (1997). Neurocircuitry of stress: central control of the hypothalamo-pituitary-adrenocortical axis. Trends Neurosci 20: 78-84

Hirayasu Y, Shenton ME, Salisbury DF, Kwon JS, Wible CG, Fischer IA et al (1999). Subgenual cingulate cortex volume in first-episode psychosis. Am J Psychiatry 156: 1091-1093.

Hof PR, Haroutunian V, Friedrich Jr VL, Byne W, Buitron C, Perl DP et al. Loss and altered spatial distribution of oligodendrocytes in the superior frontal gyrus in schizophrenia. Biol Psychiatry, 2003 53: 1075-1085.

Hof PR, Haroutunian V, Copland C, Davis KL, Buxbaum JD (2002). Molecular and cellular evidence for an oligodendrocyte abnormality in schizophrenia. Neurochem Res 27: 1193-1200.

Holthoff VA, Beuthien-Baumann B, Zundorf G, Triemer A, Ludecke S, Winiecki P et al (2004). Changes in brain metabolism associated with remission in unipolar major depression. Acta Psychiatr Scand 110: 184-194.

Honer WG, Falkai P, Chen C, Arango V, Mann JJ, Dwork AJ (1999). Synaptic and plasticity-associated proteins in anterior frontal cortex in severe mental illness. Neuroscience 91: 1247-1255.

Horovitz Z (1966). The amygdala and depression. In: Garattini S, Dukes M (eds). Antidepressant Drugs. Excerpta Medica: Amsterdam. pp 121-129.

Hsu DT, Price JL (2007). Midline and intralaminar thalamic connections with the orbital and medial prefrontal networks in macaque monkeys. J Comp Neurol 504: 89-111.

Hsu DT, Price JL (2009). Paraventricular thalamic nucleus: subcortical connections and innervation by serotonin, orexin, and corticotropin-releasing hormone in macaque monkeys. J Comp Neurol 512: 825-848.
Husain MM, McDonald WM, Doraiswamy PM, Figiel GS, Na C, Escalona PR et al (1991). A magnetic resonance imaging study of putamen nuclei in major depression. Psychiatry Res 40: 95-99.

Inagaki M, Yoshikawa E, Kobayakawa M, Matsuoka Y, Sugawara Y, Nakano T et al (2007). Regional cerebral glucose metabolism in patients with secondary depressive episodes after fatal pancreatic cancer diagnosis. J Affect Disord 99: $231-236$

llinsky IA, Jouandet ML, Goldman-Rakic PS (1985). Organization of the nigrothalamocortical system in the rhesus monkey. J Comp Neurol; 236: 315-330.

Izquierdo A, Wellman CL, Holmes A (2006). Brief uncontrollable stress causes dendritic retraction in infralimbic cortex and resistance to fear extinction in mice. J Neurosci 26: 5733-5738.

Jackson ME, Moghaddam B (2001). Amygdala regulation of nucleus accumbens dopamine output is governed by the prefrontal cortex. I Neurosci 21: 676-681.

Jaferi A, Bhatnagar S (2006). Corticosterone can act at the posterior paraventricular thalamus to inhibit hypothalamic-pituitary-adrenal activity in animals that habituate to repeated stress. Endocrinology 147: 4917-4930.

James W (1884). What is an emotion? Mind 9: 188-205.

Johnston-Wilson NL, Sims CD, Hofmann JP, Anderson L, Shore AD, Torrey EF et al (2000). Disease-specific alterations in frontal cortex brain proteins in schizophrenia bipolar disorder and major depressive disorder. The Stanley Neuropathology Consortium. Mol Psychiatry 5: 142-149.

Kaada BR (1960). Cingulate, posterior orbital, anterior insular and temporal pole cortex. In: Magoun HW (ed). Handbook of Physiology. Section I. Neurophysiology. American Physiological Society: Washington DC. Vol II, pp 1345-1372.

Kazama A, Bachevalier J (2009). Selective aspiration or neurotoxic lesions of orbital frontal areas 11 and 13 spared monkeys' performance on the object discrimination reversal task. J Neurosci 29: 2794-2804.

Kegeles LS, Malone KM, Slifstein M, Ellis SP, Xanthopoulos E, Keilp JG et al (2003). Response of cortical metabolic deficits to serotonergic challenge in familial mood disorders. Am J Psychiatry 160: 76-82.

Kessler RC, Chiu WT, Demler O, Walters EE (2005). Prevalence severity and comorbidity of 12-month DSM-IV disorders in the national comorbidity survey replication. Arch Gen Psychiatry 62: 617-627.

Ketter TA, Kimbrell TA, George MS, Dunn RT, Speer AM, Benson BE et al (2001). Effects of mood and subtype on cerebral glucose metabolism in treatmentresistant bipolar disorder. Biol Psychiatry 49: 97-109.

Kluver H, Bucy PC (1939). Preliminary analysis of functions of the temporal lobes in monkeys. Arch Neurol \& Psychiat 42: 979-1000.

Knutson B, Bhanji JP, Cooney RE, Atlas LY, Gotlib $\Vdash H$ (2008). Neural responses to monetary incentives in major depression. Biol Psychiatry 63: 686-692.

Kondo H, Saleem KS, Price JL (2005). Differential connections of the perirhinal and parahippocampal cortex with the orbital and medial prefrontal networks in macaque monkeys. J Comp Neurol 493: 479-509.

Koo MS, Levitt JJ, Salisbury DF, Nakamura M, Shenton ME, Mccarley RW (2008). A cross-sectional and longitudinal magnetic resonance imaging study of cingulate gyrus gray matter volume abnormalities in first-episode schizophrenia and first-episode affective psychosis. Arch Gen Psychiatry 65: 746-760.

Krettek JE, Price JL (1978a). Amygdaloid projections to subcortical structures within the basal forebrain and brainstem in the rat and cat. J Comp Neurol 178: 225-254.

Krettek JE, Price JL (1978b). A description of the amygdaloid complex in the rat and cat with observations on intra-amygdaloid axonal connections. J Comp Neurol 178: 225-280.

Krettek JE, Price JL (1977a). The cortical projections of the mediodorsal nucleus and certain adjacent thalamic nuclei in the rat. J Comp Neurol 171: 157-192.

Krettek JE, Price JL (1977b). An autoradiographic study of projections from the amygdaloid complex to the thalamus and cerebral cortex. J Comp Neurol 172: 723-752.

Krettek JE, Price JL (1977c). The connections of the amygdaloid complex and related olfactory cortical areas with the entorhinal cortex and the hippocampus. J Comp Neurol 172: 723-752.

Krishnan KR, Doraiswamy PM, Lurie SN, Figiel GS, Husain MM, Boyko OB et al (1991). Pituitary size in depression. [see comments]. J Clin Endocrinol Metabol 72: 256-259.

Krishnan KR, McDonald WM, Doraiswamy PM, Tupler LA, Husain M, Boyko OB et al (1993). Neuroanatomical substrates of depression in the elderly. Eur Arch Psychiatry Neurosci 243: 41-46.

Krishnan KR, McDonald WM, Escalona PR, Doraiswamy PM, Na C, Husain MM et al (1992). Magnetic resonanace imaging of the caudate nuclei in depression: Preliminary observations. Arch Gen Psychiatry 49: 553-557. 
Kruger S, Seminowicz D, Goldapple K, Kennedy SH, Mayberg HS (2003). State and trait influences on mood regulation in bipolar disorder: blood flow differences with an acute mood challenge. Biol Psychiatry 54: 1274-1283.

Krystal JH, Sanacora G, Blumberg H, Anand A, Charney DS, Marek G et al (2002). Glutamate and GABA systems as targets for novel antidepressant and moodstabilizing treatments. Mol Psychiatry 7(Suppl 1): S71-S80.

Kumano H, Ida I, Oshima A, Takahashi K, Yuuki N, Amanuma M et al (2006). Brain metabolic changes associated with predispotion to onset of major depressive disorder and adjustment disorder in cancer patients -A preliminary PET study. J Psychiatr Res 41: 591-599.

Kuroda M, Price JL (1991a). Synaptic organization of projections from basal forebrain structures to the mediodorsal thalamic nucleus of the rat. $J$ Comp Neurol 303: 513-533.

Kuroda M, Price JL (1991b). Ultrastructure and synaptic organization of axon terminals from brainstem structures to the mediodorsal thalamic nucleus of the rat. J Comp Neurol 313: 539-552.

Lambert G, Johansson M, Agren H, Friberg P (2000). Reduced brain norepinephrine and dopamine release in treatment-refractory depressive illness: evidence in support of the catecholamine hypothesis of mood disorders. Arch Gen Psychiatry 57: 787-793.

Ledoux J (2003). The emotional brain fear and the amygdala. Cell Mol Neurobiol 23: 727-738.

Likhtik E, Pelletier JG, Paz R, Pare D (2005). Prefrontal control of the amygdala. J Neurosci 25: 7429-7437.

Liotti M, Mayberg HS, McGinnis S, Brannan SL, Jerabek P (2002). Unmasking disease-specific cerebral blood flow abnormalities: mood challenge in patients with remitted unipolar depression. Am J Psychiatry 159: 1830-1840.

Lopez JF, Palkovits M, Arato M, Mansour A, Akil H, Watson SJ (1992). Localization and quantification of pro-opiomelanocortin mRNA and glucocorticoid receptor mRNA in pituitaries of suicide victims. Neuroendocrinology 56: 491-501.

Lyoo IK, Kim MJ, Stoll AL, Demopulos CM, Parow AM, Dager SR et al (2004). Frontal lobe gray matter density decreases in bipolar I disorder. Biol Psychiatry 55: 648-651.

MacFall JR, Payne ME, Provenzale JE, Krishnan KR (2001). Medial orbital frontal lesions in late-onset depression. Biol Psychiatry 49: 803-806.

Maclean PD (1949). Psychosomatic disease and the 'visceral brain'. Recent developments bearing on the Papez Theory of emotion. Psychosom Med 11: 338-353.

Mah L, Zarate Jr CA, Singh J, Duan YF, Luckenbaugh DA, Manji HK et al (2007). Regional cerebral glucose metabolic abnormalities in bipolar II depression. Biol Psychiatry 61: 765-775.

Malone Jr DA, Dougherty DD, Rezai AR, Carpenter LL, Friehs GM, Eskandar EN et al (2009). Deep brain stimulation of the ventral capsule/ventral striatum for treatment-resistant depression. Biol Psychiatry 65: 267-275.

Manij HK, Drevets WC, Charney DS (2001). The cellular neurobiology of depression. Nature Medicine 7: 541-547.

Martinez P, Ronsaville D, Gold PW, Hauser P, Drevets WC (2002). Morphometric abnormalities in adolescent offspring of depressed mothers. Soc Neurosci Abstr 32.

Martin-Soelch C, Szczepanik J, Fromm S, Barhaghi K, Wang H, Drevets W (2008). Catecholamine depletion Affects Amygdala Response to Reward: An fMRl-study. Program No. 520.10. Neuroscience Meeting Planner. Society for Neuroscience: Washington, DC (online).

Matute C, Sanchez-Gomez MV, Martinez-Millan L, Miledi R (1997). Glutamate receptor-mediated toxicity in optic nerve oligodendrocytes. Proc Natl Acad Sci USA 94: 8830-8835.

Mayberg HS, Brannan SK, Mahurin RK, Jerabek PA, Brickman JS, Tekell JL et al (1997). Cingulate function in depression: a potential predictor of treatment response. Neuroreport 8: 1057-1061.

Mayberg HS, Brannan SK, Tekell JL, Silva JA, Mahurin RK, Mcginnis S et al (2000). Regional metabolic effects of fluoxetine in major depression: serial changes and relationship to clinical response. Biol Psychiatry 48: 830-843.

Mayberg HS, Liotti M, Brannan SK, Mcginnis S, Mahurin RK, Jerabek PA et al (1999). Reciprocal limbic-cortical function and negative mood: converging PET findings in depression and normal sadness. Am J Psychiatry 156: 675-682.

Mayberg HS, Lozano AM, Voon V, Mcneely HE, Seminowicz D, Hamani C et al (2005). Deep brain stimulation for treatment-resistant depression. Neuron 45 : 651-660.

McBride SA, Slotnick B (1997). The olfactory thalamocortical system and odor reversal learning examined using an asymmetrical lesion paradigm in rats. Behav Neurosci 111: 1273-1284.

McDonald AJ (2003). Is there an amygdala and how far does it extend? An anatomical perspective. Ann NY Acad Sci 985: 1-21.
McDonald C, Bullmore ET, Sham PC, Chitnis X, Wickham H, Bramon E et al (2004). Association of genetic risks for schizophrenia and bipolar disorder with specific and generic brain structural endophenotypes. Arch Gen Psychiatry 61: 974-984.

McDonald JW, Levine JM, QU Y (1998). Multiple classes of the oligodendrocyte lineage are highly vulnerable to excitotoxicity. Neuroreport 9: 2757-2762.

McEwen BS, Magarinos AM (2001). Stress and hippocampal plasticity: implications for the pathophysiology of affective disorders. Hum Psychopharmacol 16: S7-S19.

Meyer JH, Kruger S, Wilson AA, Christensen BK, Goulding VS, Schaffer A et al (2001). Lower dopamine transporter binding potential in striatum during depression. Neuroreport 12: 4121-4125.

Miller B, Saleem KS, Price JL (2008). Cingulate Cortex Connections with Prefrontal Cortex Circuits in Monkeys. Program No. 465.11. Neuroscience Meeting Planner. Society for Neuroscience: Washington, DC (online).

Mogg K, Bradbury KE, Bradley BP (2006). Interpretation of ambiguous information in clinical depression. Behav Res Ther 44: 1411-1419.

Moore GJ, Cortese BM, Glitz DA, Zajac-Benitez C, Quiroz JA, Unde TW et al. (2009) A longitudinal study of the effects of lithium treatment on prefrontal and subgenual prefrontal gray matter volume in treatment-responsive bipolar disorder patients. J Clin Psychiatry 70: 699-705.

Morgan MA, Ledoux JE (1995). Differential contribution of dorsal and ventral medial prefrontal cortex to the acquisition and extinction of conditioned fear in rats. Behav Neurosci 109: 681-688.

Murase S, Grenhoff J, Chouvet G, Gonon FG, Svensson TH (1993). Prefrontal cortex regulates burst firing and transmitter release in rat mesolimbic dopamine neurons studied in vivo. Neurosci Lett 157: 53-56.

Murphy FC, Sahakian BJ, Rubinsztein JS, Michael A, Rogers RD, Robbins TW et al (1999). Emotional bias and inhibitory control processes in mania and depression. Psychol Med 29: 1307-1321.

Murray LA, Whitehouse WG, Alloy LB (1999). Mood congruence and depressive deficits in memory: a forced-recall analysis. Memory 7: 175-196.

Nahas Z, Teneback C, Chae JH, Mu Q, Molnar C, Kozel FA et al (2007). Serial vagus nerve stimulation functional MRI in treatment-resistant depression. Neuropsychopharmacology 32: 1649-1660.

Nauta WJ (1961). Fibre degeneration following lesions of the amygdaloid complex in the monkey. J Anat 95: 515-531.

Nauta WJ (1962). Neural associations of the amygdaloid complex in the monkey. Brain 85: 505-520.

Nestler EJ, Carlezon Jr WA (2006). The mesolimbic dopamine reward circuit in depression. Biol Psychiatry 59: 1151-1159.

Neumeister A, Drevets WC, Belfer I, Luckenbaugh DA, Henry S, Bonne O et al (2006a). Effects of a alpha 2C-adrenoreceptor gene polymorphism on neural responses to facial expressions in depression. Neuropsychopharmacology 31 : 1750-1756.

Neumeister A, Hu XZ, Luckenbaugh DA, Schwarz M, Nugent AC, Bonne O et al (2006b). Differential effects of 5-HTTLPR genotypes on the behavioral and neural responses to tryptophan depletion in patients with major depression and controls. Arch Gen Psychiatry 63: 978-986.

Neumeister A, Nugent AC, Waldeck T, Geraci M, Schwarz M, Bonne O et al (2004). Neural and behavioral responses to tryptophan depletion in unmedicated patients with remitted major depressive disorder and controls. Arch Gen Psychiatry 61: 765-773.

Neumeister A, Wood S, Bonne O, Nugent AC, Luckenbaugh DA, Young T et al (2005). Reduced hippocampal volume in unmedicated remitted patients with major depression versus control subjects. Biol Psychiatry 57: 935-937.

Nobler MS, Oquendo MA, Kegeles LS, Malone KM, Campbell CC, Sackeim HA et al (2001). Decreased regional brain metabolism after ect. Am J Psychiatry 158: 305-308.

Nugent AC, Milham MP, Bain EE, Mah L, Cannon DM, Marrett S et al (2006). Cortical abnormalities in bipolar disorder investigated with MRI and voxel-based morphometry. Neuroimage 30: 485-497.

Nunn JD, Mathews A, Trower P (1997). Selective processing of concern-related information in depression. Br J Clin Psychol 36(Part 4): 489-503.

Öngür D, An X, Price JL (1998a). Prefrontal cortical projections to the hypothalamus in macaque monkeys. J Comp Neurol 401: 480-505.

Öngür D, Drevets WC, Price JL (1998b). Glial reduction in the subgenual prefrontal cortex in mood disorders. Proc Natl Acad Sci USA 95: 13290-13295.

Öngür D, Price JL (2000). The organization of networks within the orbital and medial prefrontal cortex of rats monkeys and humans. Cereb Cortex 10: 206-219.

Öngür D, Ferry AT, Price JL (2003). Architectonic subdivision of the human orbital and medial prefrontal cortex. J Comp Neurol 460: 425-449.

Osuch EA, Ketter TA, Kimbrell TA, George MS, Benson BE, Willis MW et al (2000). Regional cerebral metabolism associated with anxiety symptoms in affective disorder patients. Biol Psychiatry 48: 1020-1023. 
Padoa-Schioppa C, Assad JA (2006). Neurons in the orbitofrontal cortex encode economic value. Nature 441: 223-226.

Papez JW (1937). A proposed mechanism of emotion. Arch Neurol Psychiat 38 : 725-743.

Paul IA, Skolnick P (2003). Glutamate and depression: clinical and preclinical studies. Ann NY Acad Sci 1003: 250-272.

Perez-Jaranay JM, Vives F (1991). Electrophysiological study of the response of medial prefrontal cortex neurons to stimulation of the basolateral nucleus of the amygdala in the rat. Brain Res 564: 97-101.

Petrides M, Pandya DN (1999). Dorsolateral prefrontal cortex: comparative cytoarchitectonic analysis in the human and the macaque brain and corticocortical connection patterns. Eur J Neurosci 11: 1011-1036.

Pezawas L, Meyer-Lindenberg A, Drabant EM, Verchinski BA, Munoz KE, Kolachana BS et al (2005). 5-HTTLPR polymorphism impacts human cingulate-amygdala interactions: a genetic susceptibility mechanism for depression. Nat Neurosci 8: 828-834.

Phelps EA, Deigado MR, Nearing Kl, LeDoux JE (2004). Extinction learning in humans: role of the amygdala and vmPFC. Neuron 43: 897-905.

Pizzagalli D, Pascual-Marqui RD, Nitschke JB, Oakes TR, Larson CL, Abercrombie $\mathrm{HC}$ et al (2001). Anterior cingulate activity as a predictor of degree of treatment response in major depression: evidence from brain electrical tomography analysis. Am J Psychiatry 158: 405-415.

Pizzagalli DA, Oakes TR, Fox AS, Chung MK, Larson CL, Abercrombie HC et al (2004). Functional but not structural subgenual prefrontal cortex abnormalities in melancholia. Mol Psychiatry 9: 393-405.

Porrino LJ, Crane AM, Goldman-Rakic PS (1981). Direct and indirect pathways from the amygdala to the frontal lobe in rhesus monkeys. J Comp Neurol 198: $121-136$.

Price $J L$ (2003). The olfactory system. In: Paxinos G (ed). The Human Nervous System, 2nd edn. Academic Press: San Diego. pp 1198-1212.

Price JL (2006). The prefrontal cortex. In: Moldin S, Rubenstein J (eds). Understanding Autism. CRC Press: Boca Raton, FL. pp 205-226.

Price JL, Amaral DG (1981). An autoradiographic study of the projections of the central nucleus of the monkey amygdala. J Neurosci 11: 1242-1259.

Price JL, Carmichael ST, Drevets WC (1996). Networks related to the orbital and medial prefrontal cortex; a substrate for emotional behavior? Prog Brain Res 107: 523-536.

Pritchard TC, Nedderman EN, Edwards EM, Petticoffer AC, Schwartz GJ, Scott TR (2008). Satiety-responsive neurons in the medial orbitofrontal cortex of the macaque. Behav Neurosci 122: 174-182.

Radley JJ, Rocher AB, Rodriguez A, Ehlenberger DB, Dammann M, McEwen BS et al (2008). Repeated stress alters dendritic spine morphology in the rat medial prefrontal cortex. J Comp Neurol 507: 1141-1150.

Raichle ME, MacLeod AM, Snyder AZ, Powers WJ, Gusnard DA, Shulman GL (2001). A default mode of brain function. Proc Natl Acad Sci USA 98: 676-682.

Rajkowska G, Halaris A, Selemon LD (2001). Reductions in neuronal and glial density characterize the dorsolateral prefrontal cortex in bipolar disorder. Biol Psychiatry 49: 741-752.

Rajkowska G, Miguel-Hidalgo JJ (2007). Gliogenesis and glial pathology in depression. CNS Neurol Disord Drug Targets 6: 219-233.

Rajkowska G, Miguel-Hidalgo JJ, Wei J, Dilley G, Pittman SD, Meltzer HY et al (1999). Morphometric evidence for neuronal and glial prefrontal cell pathology in major depression. Biol Psychiatry 45: 1085-1098.

Rajkowska G, O'Dwyer G, Teleki Z, Stockmeier CA, Miguel-Hidalgo JJ (2007). GABAergic neurons immunoreactive for calcium binding proteins are reduced in the prefrontal cortex in major depression. Neuropsychopharmacology 32: 471-482.

Ray JP, Price JL (1992). The organization of the thalamocortical connections of the mediodorsal thalamic nucleus in the rat related to the ventral forebrain-prefrontal cortex topography. J Comp Neurol 323: 167-197.

Ray JP, Price JL (1993). The organization of projections from the mediodorsal nucleus of the thalamus to orbital and medial prefrontal cortex in macaque monkeys. J Comp Neurol 337: 1-31.

Regenold WT, Phatak P, Marano CM, Gearhart L, Viens CH, Hisley KC (2007). Myelin staining of deep white matter in the dorsolateral prefrontal cortex in schizophrenia bipolar disorder and unipolar major depression. Psychiatry Res 151: 179-188.

Rempel-Clower NL, Barbas H (1998). Topographic organization of connections between the hypothalamus and prefrontal cortex in the rhesus monkey. J Comp Neurol 398: 393-419.

Roberts AC, Robbins TW, Everitt BJ, Jones GH, Sirkia TE, Wilkinson J et al (1990). The effects of excitotoxic lesions of the basal forebrain on the acquisition retention and serial reversal of visual discriminations in marmosets. Neuroscience 34: 311-329.

Rolls ET (2000). The orbitofrontal cortex and reward. Cereb Cortex 10: 284-294.
Romanski LM (2007). Representation and integration of auditory and visual stimuli in the primate ventral lateral prefrontal cortex. Cereb Cortex 17(Suppl 1): i61-i69.

Rosoklija G, Toomayan G, Ellis SP, Keilp J, Mann JJ, Latov N et al (2000). Structural abnormalities of subicular dendrites in subjects with schizophrenia and mood disorders: preliminary findings. Arch Gen Psychiatry 57: 349-356.

Rudebeck PH, Murray EA (2008). Amygdala and orbitofrontal cortex lesions differentially influence choices during object reversal learning. J Neurosci 28: 8338-8343.

Russchen FT, Amaral DG, Price JL (1987). The afferent input to the magnocellular division of the mediodorsal thalamic nucleus in the monkey Macaca fascicularis. J Comp Neurol 256: 175-210.

Russchen FT, Bakst I, Amaral DG, Price JL (1985). The amygdalostriatal projections in the monkey. An anterograde tracing study. Brain Res 329: 241-257.

Saleem KS, Kondo H, Price JL (2008). Complimentary circuits connecting the orbital and medial prefrontal networks with the temporal insular and opercular cortex in the macaque monkey. J Comp Neurol 506: 659-693.

Sanacora G, Mason GF, Rothman DL, Behar KL, Hyder F, Petroff OA et al (1999). Reduced cortical gamma-aminobutyric acid levels in depressed patients determined by proton magnetic resonance spectroscopy. Arch Gen Psychiatry 56: 1043-1047.

Santamaria J, Tolosa E, Valles A (1986). Parkinson's disease with depression: a possible subgroup of idiopathic parkinsonism. Neurology 36: 1130-1133.

Santarelli L, Saxe M, Gross C, Surget A, Battaglia F, Dulawa S et al (2003). Requirement of hippocampal neurogenesis for the behavioral effects of antidepressants. Science 301: 805-809.

Savitz J, Nugent AC, Bogers W, Liu A, Sills R, Luckenbaugh DA et al (2009). Amygdala volume in bipolar disorder assessed using high resolution 3T MRI: the impact of medication. Neuroimage (in press).

Schlaepfer TE, Cohen MX, Frick C, Kosel M, Brodesser D, Axmacher N et al (2008). Deep brain stimulation to reward circuitry alleviates anhedonia in refractory major depression. Neuropsychopharmacology 33: 368-377.

Schultz W, Dayan P, Montague PR (1997). A neural substrate of prediction and reward. Science 275: 1593-1599.

Shansky RM, Hamo C, Hof PR, McEwen BS, Morrison JH (2009). Stress-induced dendritic remodeling in the prefrontal cortex is circuit specific. Cereb Cortex; e-pub ahead of print.

Shekhar A, Truitt W, Rainnie D, Sajdyk T (2005). Role of stress corticotrophin releasing factor (CRF) and amygdala plasticity in chronic anxiety. Stress 8: 209-219.

Sheline YI, Barch DM, Donnelly JM, Ollinger JM, Snyder AZ, Mintun MA (2001). Increased amygdala response to masked emotional faces in depressed subjects resolves with antidepressant treatment: an fMRI study. Biol Psychiatry 50: $651-658$.

Sheline YI, Gado MH, Kraemer HC (2003). Untreated depression and hippocampal volume loss. Am J Psychiatry 160: 1516-1518.

Shulman RG, Rothman DL, Behar KL, Hyder F (2004). Energetic basis of brain activity: implications for neuroimaging. Trends Neurosci 27: 489-495.

Si X, Miguel-Hidalgo JJ, O'Dwyer G, Stockmeier CA, Rajkowska G (2004). Agedependent reductions in the level of glial fibrillary acidic protein in the prefrontal cortex in major depression. Neuropsychopharmacology 29: 2088-2096.

Siegle GJ, Carter CS, Thase ME (2006). Use of FMRI to predict recovery from unipolar depression with cognitive behavior therapy. Am J Psychiatry 163: 735-738.

Siegle GJ, Steinhauer SR, Thase ME, Stenger VA, Carter CS (2002). Can't shake that feeling: event-related $\mathrm{fMRI}$ assessment of sustained amygdala activity in response to emotional information in depressed individuals. Biol Psychiatry 51: 693-707.

Spencer SJ, Fox JC, Day TA (2004). Thalamic paraventricular nucleus lesions facilitate central amygdala neuronal responses to acute psycho- logical stress. Brain Res 997: $234-237$

Stockmeier CA, Mahajan GJ, Konick LC, Overholser JC, Jurjus GJ, Meltzer HY et al (2004). Cellular changes in the postmortem hippocampus in major depression. Biol Psychiatry 56: 640-650.

Sullivan RM, Gratton A (1999). Lateralized effects of medial prefrontal cortex lesions on neuroendocrine and autonomic stress responses in rats. J Neurosci 19: 2834-2840.

Surguladze S, Brammer MJ, Keedwell P, Giampietro V, Young AW, Travis MJ et al (2005). A differential pattern of neural response toward sad versus happy facial expressions in major depressive disorder. Biol Psychiatry 57: 201-209.

Swaab DF, Bao AM, Lucassen PJ (2005). The stress system in the human brain in depression and neurodegeneration. Ageing Res Rev 4: 141-194.

Taber MT, Fibiger HC (1993). Electrical stimulation of the medial prefrontal cortex increases dopamine release in the striatum. Neuropsychopharmacology 9: $271-275$. 
Taylor-Tavares JV, Clark L, Furey ML, Williams GB, Sahakian BJ, Drevets WC (2008). Neural basis of abnormal response to negative feedback in unmedicated mood disorders. Neuroimage 42: 1118-1126.

Terreberry RR, Neafsey EJ (1987). The rat medial frontal cortex projects directly to autonomic regions of the brainstem. Brain Res Bull 19: 639-649.

Teves D, Videen TO, Cryer PE, Powers WJ (2004). Activation of human medial prefrontal cortex during autonomic responses to hypoglycemia. Proc Natl Acad Sci USA 101: 6217-6221.

Todtenkopf MS, Vincent SL, Benes FM (2005). A cross-study meta-analysis and three-dimensional comparison of cell counting in the anterior cingulate cortex of schizophrenic and bipolar brain. Schizophr Res 73: 79-89.

Tsao DY, Schweers N, Moeller S, Freiwald WA (2008). Patches of face-selective cortex in the macaque frontal lobe. Nat Neurosci 11: 877-879.

Uranova N, Orlovskaya D, Vikhreva O, Zimina I, Kolomeets N, Vostrikov V et al (2001). Electron microscopy of oligodendroglia in severe mental illness. Brain Res Bull 55: 597-610.

Uranova NA, Vostrikov VM, Orlovskaya DD, Rachmanova VI (2004). Oligodendroglial density in the prefrontal cortex in schizophrenia and mood disorders: a study from the Stanley Neuropathology Consortium. Schizophr Res 67: 269-275.

Van Laere K, Nuttin B, Gabriels L, Dupont P, Rasmussen S, Greenberg BD et al (2006). Metabolic imaging of anterior capsular stimulation in refractory obsessivecompulsive disorder: a key role for the subgenual anterior cingulate and ventral striatum. J Nucl Med 47: 740-747.

Vidal-Gonzalez I, Vidal-Gonzalez B, Rauch SL, Quirk GJ (2006). Microstimulation reveals opposing influences of prelimbic and infralimbic cortex on the expression of conditioned fear. Learn Mem 13: 728-733.

Vostrikov VM, Uranova NA, Orlovskaya DD (2007). Deficit of perineuronal oligodendrocytes in the prefrontal cortex in schizophrenia and mood disorders. Schizophr Res 94: 273-280.
Vyas A, Bernal S, Chattarji S (2003). Effects of chronic stress on dendritic arborization in the central and extended amygdala. Brain Res 965: 290-294.

Vyas A, Jadhav S, Chattarji S (2006). Prolonged behavioral stress enhances synaptic connectivity in the basolateral amygdala. Neuroscience 143: 387-393.

Vyas A, Mitra R, Shankaranarayana Rao BS, Chattarji S (2002). Chronic stress induces contrasting patterns of dendritic remodeling in hippocampal and amygdaloid neurons. J Neurosci 22: 6810-6818.

Vythilingam M, Heim C, Newport J, Miller AH, Anderson E, Bronen R et al (2002). Childhood trauma associated with smaller hippocampal volume in women with major depression. Am J Psychiatry 159: 2072-2080.

Webster MJ, Knable MB, Johnston-Wilson N, Nagata K, Inagaki M, Yolken RH (2001). Immunohistochemical localization of phosphorylated glial fibrillary acidic protein in the prefrontal cortex and hippocampus from patients with schizophrenia bipolar disorder and depression. Brain Behav Immun 15: 388-400.

Wellman CL (2001). Dendritic reorganization in pyramidal neurons in medial prefrontal cortex after chronic corticosterone administration. J Neurobiol 49 245-253.

WHO (2001). The world health report. www.who.int.; Chapter 24

Williams LM, Brammer MJ, Skerrett D, Lagopolous J, Rennie C, Kozek K et al (2000). The neural correlates of orienting: an integration of $\mathrm{fMRI}$ and skin conductance orienting. Neuroreport 11: 3011-3015.

Willner P (1995). Dopaminergic mechanisms in depression and mania. In: Bloom FE, Kupfer DJ (eds). Psychopharmacology: The Fourth Generation of Progress. Raven Press: New York. pp 921-932.

Wu J, Buchsbaum MS, Gillin JC, Tang C, Cadwell S, Wiegand M et al (1999). Prediction of antidepressant effects of sleep deprivation by metabolic rates in the ventral anterior cingulate and medial prefrontal cortex. Am J Psychiatry 156: 1149-1158.

Zola-Morgan S, Squire LR, Alvarez-Royo P, Clower RP (1991). Independence of memory functions and emotional behavior: separate contributions of the hippocampal formation and the amygdala. Hippocampus 1: 207-220. 